Ryszard BIELAWsKI

\title{
Die Marienkäfer (Coleoptera: Coccinellidae) aus Nepal
}

[Mit 139 Abbildungen im Text]

Dank der Höflichkeit der Herren Dr. H. Freude und Dr. H. Fürsch (München) wurden mir die Marienkäfer aus Nepal durch die Zoologische Sammlung des Bayerischen Staates zur Bearbeitung anvertraut, wofür ich den beiden genannten Herren meinen aufrichtigsten Dank ausdrücken möchte. Das Material, das 318 Exemplare enthielt, erwies sich sehr artenreich und ich stellte nach seiner Bearbeitung 40 Arten fest, von denen 3, und zwar: Cryptogonus nepalensis sp. n., Coelophora eberti sp. n. und Calvia albida sp. n. neu für die Wissenschaft sind und 15 weitere bisher aus Nepal nicht gemeldet wurden. Die Arbeit von KAPUR (1958), die eine Liste aller aus Nepal bekannten Marienkäfer enthält und andere Arbeiten in Betracht nehmend, kann man feststellen, dass man von diesem Lande gegenwärtig 62 Coceinelliden-Arten kennt. Die Endemiten bilden den grössten Teil der bekannten Arten, die indo-malayischen Formen sind schwächer repräsentiert und die paläarktischen nur wenig vertreten.

Das Belegmaterial wird in der Zoologischen Sammlung des Bayerischen Staates in München und im Zoologischen Institut der Polnischen Akademie der Wissenschaften in Warszawa aufbewahrt.

\section{Henosepilachna sparsa orientalis (DIEKE)}

Untersuchtes Material: Sun Khosi Tal, 2150 m, 2.V.1962, 2 Ex.; Jiri, 1900 m, 17.-19.V.1962, 1 Ex.; Likhu Khola Tal, 1700 m, 1.VIII.1962, 1 Ex.

Die Unterart wurde von DIEKE (1947) beschrieben und bisher nur aus China und Japan bekannt. Oft mit $H$. vigintioctopunctata (F.) verwechselt. Neu für Nepal.

Alle untersuchten Stücke haben je 14 Flecke auf jeder Flügeldecke. Die Flecke erreichen weder keinen Rand der Decke noch fliessen miteinander 
zusammen, lediglich bei einem Exemplar berührt der ein wenig vergrösserte Fleck d die Naht. Der Fleck d liegt bei allen Exemplaren kaum näher der Naht als die anderen Flecke.

Kopulationsapparat beider Geschlechter stimmt mit den Angaben DIEKEs (1947) überein.

\section{Henosepilachna vigintioctomaculata coalescens (MAD.)}

Untersuchtes Material: Likhu Khola Tal, 1700 m, 1.VIII.1962, 3 Ex.

Die Unterart ist bisher nur aus China (Sichuan und Tibet) bekannt, Erstfund in Nepal.

MADER (1930) beschrieb die besprochene Form als Varietät, DIEKE (1947) erhob sie in den Unterartrang - Epilachna niponica coalescens. Henosepilachna niponica (LEWIS) ist mit $H$. vigintioctomaculata (МотSCH.) artgleich und der richtige Name dieser Unterart soll deshalb $H$. vigintioctomaculata coalescens (MAD.) lauten (BIELAWSKI 1960).

\section{Henosepilachna vigintioctopunctata (F.)}

Untersuchtes Material: Belephi Bazar, $1500 \mathrm{~m}, 29.1$ V.1962, 1 Ex.

Die Art ist schon früher aus Nepal bekannt geworden (KAPUR 1958) und kommt fast in der ganzen Indo-Malayischen und Australischen Region vor.

Beim untersuchten Stück treten 14 Flecke auf jeder Flügeldecke auf, von denen nur der Fleck 4 den Seitenrand erreicht und die der Naht entlang gelegenen Flecke liegen im gleichen Abstand von ihr.

Die weiblichen Genitalien des vorliegenden Exemplares stimmen mit den von mir früher (BIELAWSKI 1963) beschriebenen vollkommen überein.

\section{Henosepilachna ocellata (REDT.)}

Untersuchtes Material: Ting-Sang-La, $3800 \mathrm{~m}$, 6.-7.V.1962, 1 Ex.

Die Art kommt im Himalaja von Kaschmir an bis Nord-Bengalen hin vor. Für Nepal nachgewiesen von MuLsant (1850) als Epilachna oculea MULs., sowie von CROTCH $(1874)$ und KAPUR $(1952,1958)$ als Epilachna ocellata REDT.

\section{Afidenta misera (Ws.)}

Untersuchtes Material: Kathmandu, 1400 m, 15.IV.1962, 1 Ex.; Sun Khosi Tal, $2150 \mathrm{~m}, 2 . \mathrm{V} .1962,3 \mathrm{Ex}$.

Bisher aus China (samt Taiwan und Hongkong), Indien und Ceylon bekannt, neu für die Fauna Nepals. 
In der Literatur ist diese Art unter drei Namen bekannt, und zwar DIEKE (1947), indem er die Gattung Afidenta absondert, beschreibt A. mimetica, später von KAPUR (1958) zu A. gradaria (MULs.) und endlich von mir (BIELAWSKI 1961) zu $A$. misera. (Ws.) synonym gestellt.

Die vorliegenden Stücke haben je 6 Flecke auf jeder Flügeldecke.

\section{Epilachna hingstoni (KAPUR)}

Untersuchtes Material: Janbesi, Prov. Nr. 3 East, 25.IV.1964, 2750 m, Löfrler leg., 1 Ex.

Von KAPUR (1963) anhand zweier Weibchen aus Tibet und Indien beschrieben, neu für die Fauna Nepals.
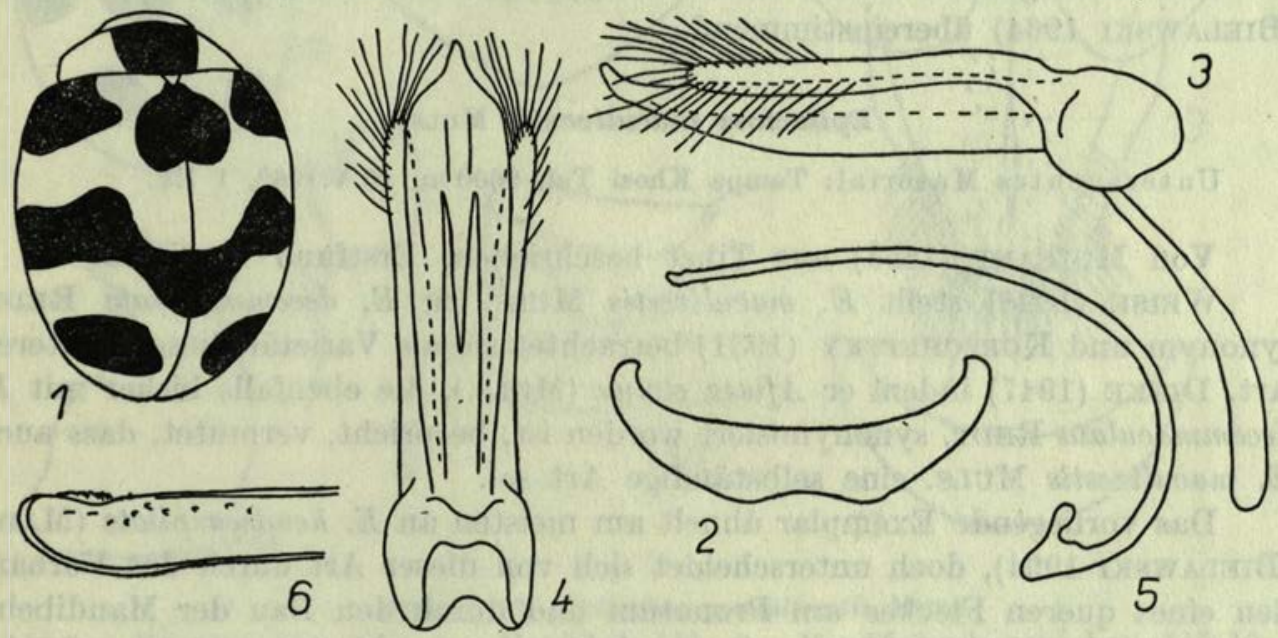

Abb. 1-6. Epilachna hingstoni (KAPUR).

Abb. 1 - Körperumriss, Abb. 2 - Letztes Sternit des Männchens, Abb. 3 und 4 - Kopulationsapparat des Männchens, Abb. 5 -Sipho, Abb. 6 - Ende des Siphos.

Mir lag ein Männchen vor. Es ist fast identisch gefärbt wie die Originalexemplare, nur die erste Querbinde der Flügeldecken zu zwei Flecken geteilt (Abb. 1). Andere Merkmale mit der Originalbeschreibung (KAPUR 1963a) übereinstimmend.

Letztes Sternit des Männchens (Abb. 2) mit deutlich eingeschnittenem Hinterrand. Letztes Tergit lang, mit bogenförmigem Hinterrand und breiten, kurzen Basalfortsätzen.

Körper 5,1 mm lang, grösste Breite $4,0 \mathrm{~mm}$.

Männlicher Kopulationsapparat (Abb. 3-4). Penis 0,93 mm lang, $0,16 \mathrm{~mm}$ breit, länger als die Parameren, schlank, von der Seite betrachtet am Ende verengt und unmerklich gekrümmt, von unten betrachtet von Basis 
ab unmerklich breiter werdend und vor dem Ende stark und jäh verengt und kurz zugespitzt. Parameren gerade, schmal, mit langer aber nicht allzu reichlicher Behaarung. Basalteil fast kreisrund. Trabes schlank, kurz, kürzer als der Penis. Sipho (Abb. 5) schlank, bogenförmig, mit kleiner Kapsel. Siphoendung wie an der Abb. 6.

Durch den Bau des Kopulationsapparates nähert sich diese Art sehr der Epilachna bengalica (DIEKE).

\section{Epilachna dumerili MuLs.}

Untersuchtes Material: Rapti Tal, Megouli, 300 m, 1.IV.1962, 5 Ex.

Bisher aus Indien, Ceylon und Burma bekannt, neu für die Fauna Nepals.

Alle vorliegenden Stücke identisch und mit der Redeskription der Art (BIELAWSKI 1964) übereinstimmend.

\section{Epilachna maculivestis MuLs.}

Untersuchtes Material: Tampa Khosi Tal, 2600 m, 10.V.1962, 1 Ex.

Von Mulsant (1853) aus Tibet beschrieben, Erstfund in Nepal.

WeISE (1898) stellt $E$. maculivestis MuLs. zu $E$. decemmaculata REDT. synonym und KoRSCHEFSKY (1931) betrachtet sie als Varietät dieser letzteren Art. DIEke (1947) indem er Afissa elvina (Muls.), die ebenfalls bisher mit $E$. decemmaculata REDT. synonymisiert worden ist, bespricht, vermutet, dass auch E. maculivestis MuLs. eine selbständige Art sei.

Das vorliegende Exemplar ähnelt am meisten an $E$. hendecaspilota (MAD.) (BIELAWSKI 1964), doch unterscheidet sich von dieser Art durch das Vorhanden eines queren Fleckes am Pronotum und durch den Bau der Mandibeln. Es entspricht andrerseits den Beschreibungen von E. elvina Muls. und $E$. decemmaculata REDT., von denen es sich durch die Körpergrösse unterscheidet. Die Körperlänge erreicht bei $E$. decemmaculata REDT. $4,8 \mathrm{~mm}$ und bei $E$. elvina MuLs. $5,0 \mathrm{~mm}$, während sie beim untersuchten Exemplar $5,6 \mathrm{~mm}$ beträgt, was mit Angaben Mulsants (1853) für $\boldsymbol{E}$. maculivestis Muls. übereinstimmt. Die Masse der Genitalplatten sind bei $E$. elvina MuLs. und $E$. maculivestis Muls. verschieden, und zwar ist die Genitalplatte bei $E$. elvina MuLs. $0,95 \mathrm{~mm}$ lang und $0,27 \mathrm{~mm}$ breit, beim untersuchten Käfer ist sie dagegen entsprechend $0,78 \mathrm{~mm}$ und $0,23 \mathrm{~mm}$. Von obigen Gründen zähle ich das vorliegende Exemplar zu der Art $E$. maculivestis MuLs., doch eine endgültige Lösung der Frage der Artbesonderheit aller drei Arten fordert der Untersuchung der männlichen Kopulationsapparate. Männlicher Kopulationsapparat ist bisher nur bei $\boldsymbol{E}$. elvina MULS. bekannt (DIEKE 1947).

Körperumriss und Dessin wurden an der Abb. 7 dargestellt. Mandibeln (Abb. 8-9) mit dreifältigem Apikalzahn, einem grossen, mit winzigen Zähn- 
chen bewehrten und einem kleinen Subapikalzahn. Schenkellinie (Abb. 10) vollständig, mit ihrer Biegung über $3 / 4$ der Segmentlänge reichend. Letztes Sternit des Weibchens (Abb. 11) stark bogenförmig, mit langer, reichlicher Behaarung. Letztes Tergit (Abb. 12) mit ziemlich langen, den Seiten zu kaum ausgebogenen Basalfortsätzen, in halber Breite fast scharf beendetem Hinterrand und sehr langer und recht reichlicher Behaarung. Der Kopulationsapparat wie an der Abb. 13.

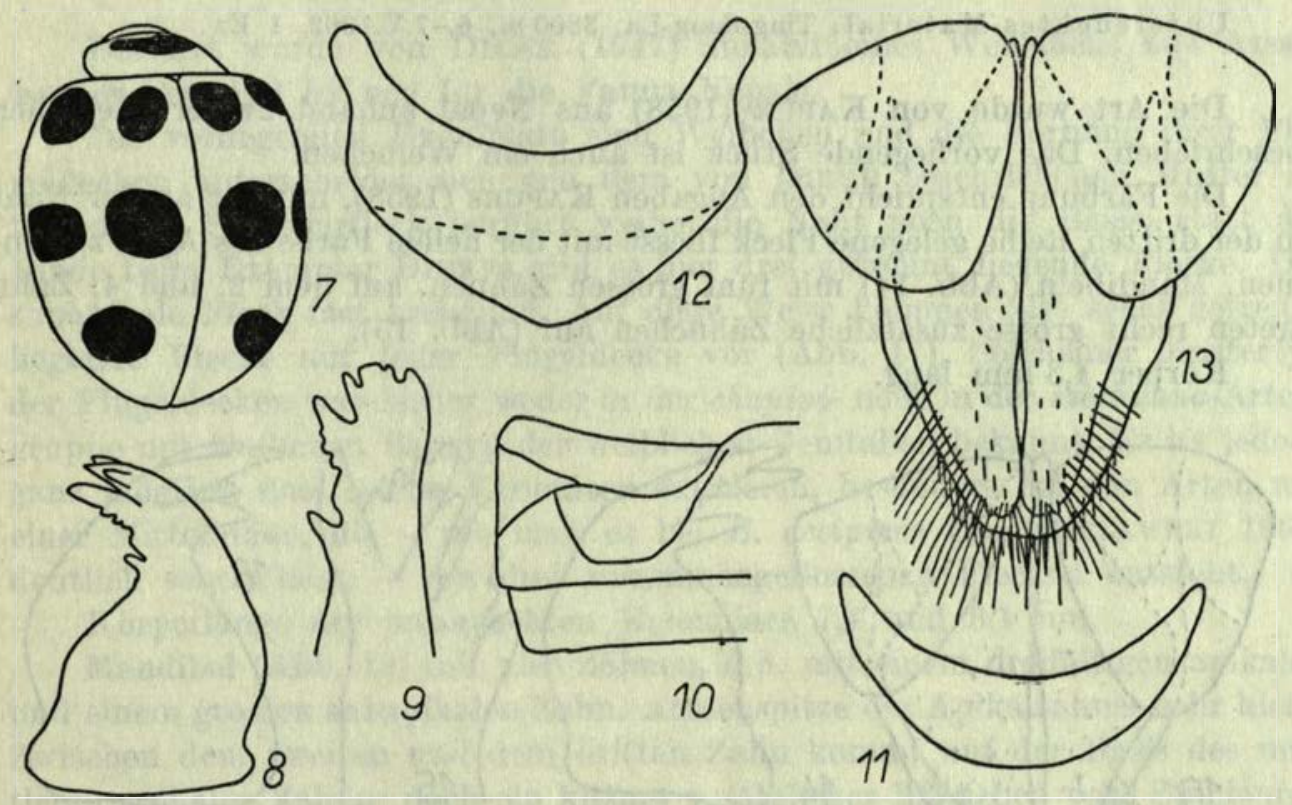

Abb. 7-13. Epilachna maculivestis MuLs.

Abb. 7 - Körperumriss, Abb. 8 - Mandibel, Abb. 9 - Mandibelende von oben, Abb.10 Schenkellinie, Abb. 11 - Letztes Sternit des Weibchens, Abb. 12 - Letztes Tergit des Weibchens, Abb. 13 - Weiblicher Kopulationsapparat.

\section{Epilachna mysticoides (Sic.)}

Untersuchtes Material: Thodung, Prov. Nr. 2 East, $3200 \mathrm{~m}$, 14.-21.IV.1964, W. Dierl leg., 3 Ex.; Puiyan, Prov. Nr. 3 East, 26.VI.1964, 2900 m, LöFrler leg., 2 Ex.

Die Art wurde aus Indien beschrieben (SICARD 1912) und später aus dem Himalaja (DIEKE 1947) und aus Nepal (KAPUR 1958) gemeldet.

Die vorliegenden Stücke haben am Pronotum einen grossen queren Fleck und auf den Flügeldecken je fünf Flecke, von denen der Schulterfleck den Schulterhöcker umgibt und sich bisweilen mit dem Scutellarfleck verknüpfen kann.

Männlicher Kopulationsapparat wie von KAPUR (1958) angegeben. 


\section{Epilachna mystica MuLs.}

Untersuchtes Material: Ting-Sang-La, 3800 m, 6.-7.V.1962, 1 Ex.; Tampa Khosi Tal, $2600 \mathrm{~m}, 10$. V.1962, $1 \mathrm{Ex}$.

Die Art wurde aus Nepal von KAPUR (1958) gemeldet, sie ist ausserdem aus Sikkim, Nord-Bengalen und Burma bekannt.

\section{Epilachna nepalensis (KAPUR)}

Untersuchtes Material: Ting-Sang-La, $3800 \mathrm{~m}, 6 .-7 . V .1962,1 \mathrm{Ex}$.

Die Art wurde von KAPUR (1958) aus Nepal anhand zweier Weibchen beschrieben. Das vorliegende Stück ist auch ein Weibchen.

Die Färbung entspricht den Angaben KAPURs (1958), nur der an der Naht in der dritten Reihe gelegene Fleck fliesst mit der hellen Farbe des Apex zusammen. Mandibeln (Abb. 14) mit fünf grossen Zähnen, auf dem 2. und 4. Zahn treten recht grosse zusätzliche Zähnchen auf (Abb. 15).

Körper 4,3 mm lang.

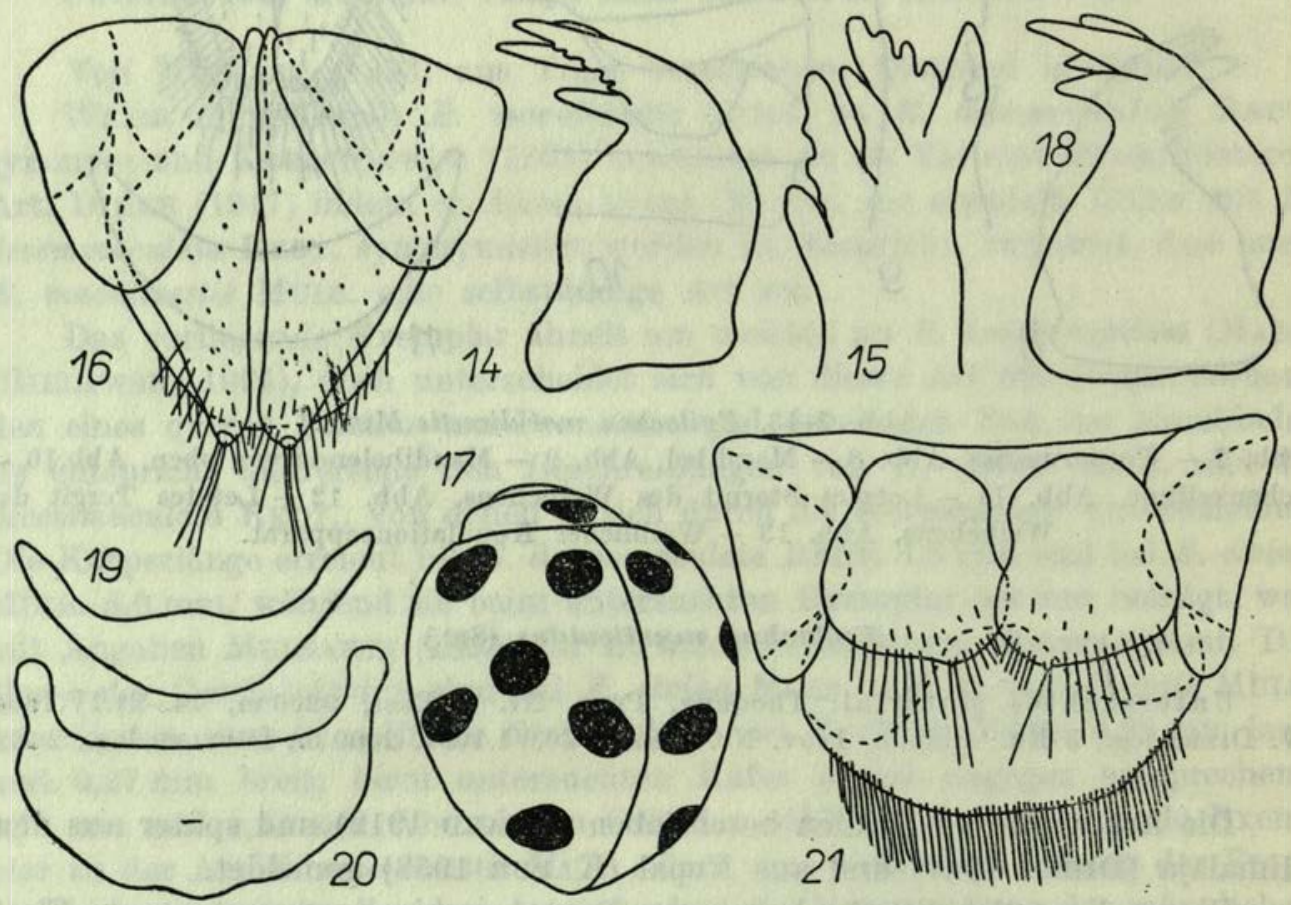

Abb. 14-21.

Abb. 14-16. Epilachna nepalensis (KAPUR). Abb. 17-21. Epilachna militaris (DIEKE). Abb. 14 und 18 - Mandibel, Abb. 15 - Mandibelende von oben, Abb. 16 und 21 - Weiblicher Kopulationsapparat, Abb. 17 - Körperumriss, Abb. 19 - Letztes Sternit des Weibehens, Abb. 20 - Letztes Tergit des Weibchens. 
Weiblicher Kopulationsapparat (Abb. 16). Die Gestalt der Genitalplatte mit der Abbildung bei KAPUR übereinstimmend. Länge der Genitalplatte $0,65 \mathrm{~mm}$, grösste Breite (in halber Länge) $0,24 \mathrm{~mm}$.

\section{Epilachna militaris (DIEKE)}

Untersuchtes Material: Rapti Tal, Megouli, 300 m, 1.IV.1962, 1 Ex.; Sun Khosi Tal, $2150 \mathrm{~m}, 2 . \mathrm{V} .1962,1 \mathrm{Ex}$.

Die Art wurde von DIEKe (1947) anhand eines Weibchens aus Assam beschrieben und ist neu für die Fauna Nepals.

Die vorliegenden Exemplare sind Weibchen und die Färbung ihrer Flügeldecken unterscheidet sich von dem von DIEKE beschriebenen Muster im folgenden: Scutellarfleck berührt weder die Naht noch die Basis, statt der Binde beim Exemplar DIEKEs gibt es hier drei getrennt liegende Flecke. Der subapikale Fleck fast kreisrund. Auf diese Weise kommen also sechs getrennt liegende Flecke auf jeder Flügeldecke vor (Abb. 17). Solcheiner Mustertyp der Flügeldecken war bisher weder in der chapini- noch in der szechuana-Artengruppe mit ähnlichen Bautyp der weiblichen Genitalien bekannt. Es ist jedoch ganz möglich, dass solche Varietäten existieren, besonders bei den Arten mit einer Mittelbinde, die - wie man es bei $E$. decipiens Cr. (BIELAWSKI 1961) deutlich sehen kann - von drei zusammengeflossenen Flecken entsteht.

Körperlänge der untersuchten Exemplare 7,4 und $8,1 \mathrm{~mm}$.

Mandibel (Abb. 18) mit vier Zähnen, d.h. mit einem dreifältigen apikalen und einem grossen subapikalen Zahn. Aussenspitze des Apikalzahnes sehr klein. Zwischen dem zweiten und dem dritten Zahn kommt auf der Basis des mittleren apikalen Zahnes noch ein kleines zusätzliches Zähnchen vor. Epipleuren der Flügeldecken mit deutlichen Einbuchtungen für die Enden der Schenkel. Letztes Sternit des Weibchens (Abb. 19) sehr kurz, stark bogenförmig gekrümmt, nicht allzu kurz und sehr reichlich behaart. Letztes Tergit (Abb. 20) mit unmerklich gewelltem Hinterrand, kurzen und ziemlich schmalen Basalfortsätzen, recht lang und reichlich behaart.

Weiblicher Kopulationsapparat wie an der Abb. 21.

\section{Afissula rana KAPUR}

Untersuchtes Material: Tampa Khosi Tal, 2600 m, 10.V.1962, 1 Ex.; Jiri, 1900 m, 17.-19.V.1962, $3 \mathrm{Ex}$.

Die Art wurde von Nepal beschrieben (KAPUR 1958). Zwei der untersuchten Exemplare sind identisch gefärbt wie in der Originalbeschreibung angegeben und bei zwei anderen ist der Schulterfleck mit dem Scutellarfleck verknüpft. Männliche Genitalien mit den Angaben KAPURs (1958) übereinstimmend. Siphoendung wie an der Abb. 22. 

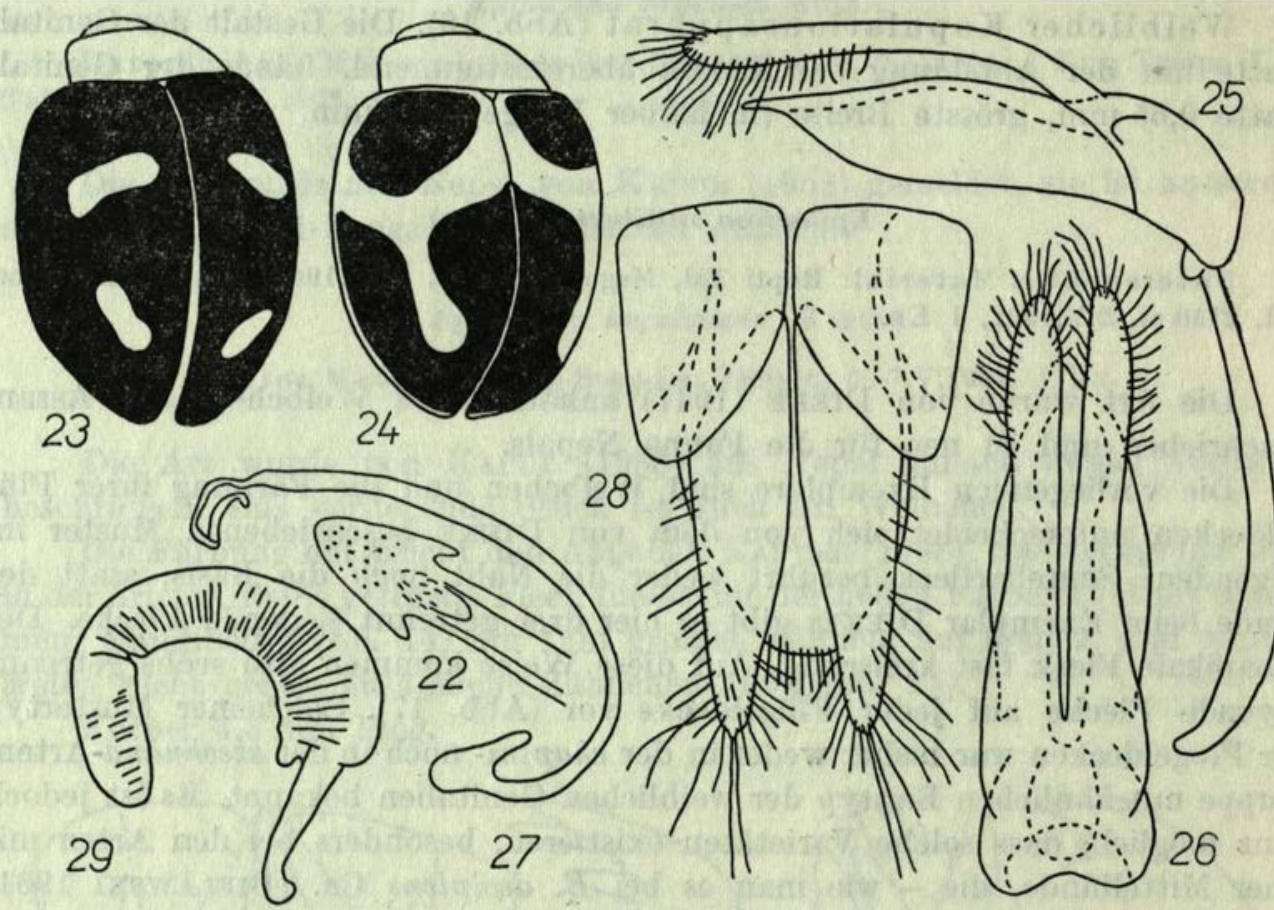

Abb. 22-29.

Abb. 22 - Afissula rana KAPUR, Ende des Siphos von oben, Abb. 23-29 - Sumnius vestita (Muls.), Abb. 23 und 24 - Körperumriss, Abb. 25 und 26 - Kopulationsapparat des Männchens, Abb. 27 - Sipho, Abb. 28 - Weiblicher Kopulationsapparat, Abb. 29 - Receptaculum seminis.

\section{Sumnius vestita (MuLs.)}

Untersuchtes Material: Bhimpedi Tal, 400 m, 4.-7.IV.1962, G. EBERT leg., 5 Ex.; Kathmandu, $1400 \mathrm{~m}, 10 .-14 . I V .1962$, G. EBERT leg., 1 Ex.

Neu für die Fauna Nepals.

Die untersuchten Exemplare sind zweierlei gefärbt. Bei 4 Stücken kommen je zwei dunkelrote Flecke auf schwarzem Hintergrund jeder Flügeldecke vor (Abb. 23) und bei zwei anderen sind diese Flecke miteinander verknüpft und bilden ein spezifisches Muster (Abb. 24). Ausser den Unterschieden in Färbung der Flügeldecken sind alle Exemplare vollkommen gleich und gehören einer und derselben Art zweifellos an. Ich rechne sie zu S. vestita (MULs.), obwohl die Stücke mit den Flecken ebenfalls anderen Arten, z.B. S. notivestis (MULs.) entsprächen. Die Artbesonderheit aller asiatischen Arten dieser Gattung ruft grosse Zweifel hervor und kann nur durch genitalmorphologische Untersuchung aller Typen entschieden werden. Die Gattungsangehörigkeit ist ebenfalls problematisch - es handelt sich hier um die Gattungen entweder 
Sumnius Ws. oder Aulis MuLs. Das Fehlen an genügenden Angaben betreffs Morphologie aller asiatischen Arten (Sumnius cardoni Ws., S. renardi Ws., S. yunnanus MADER, Aulis haematica GoRH., A. notivestis MULs., A. vestita MULS.) und zugleich - soviel man aus den bisherigen Beschreibungen erkennen kann ihre grosse Ähnlichkeit rufen Vermutung hervor, dass all diese Arten einer und derselben Gattung angehören sollten. Da die meisten Arten der Gattung Aulis Muls. in der Äthiopischen Region vorkommen, rechne ich die asiatischen Arten vorläufig der Gattung Sumnius Ws. zu, die in solcher Auffassung nur asiatische Formen umfasste. Das Problem wird aber dadurch noch nicht endgültig entschieden.

Der Kopulationsapparat beider Geschlechter wird an den Abb. 25-29 dargestellt. Penis $0,8 \mathrm{~mm}$ lang, höchstens $0,22 \mathrm{~mm}$ breit. Genitalplatte $0,72 \mathrm{~mm}$ lang, höchstens $0,18 \mathrm{~mm}$ breit.

\section{Rodolia octoguttata Ws.}

Untersuch tes Material: Bi Khola Tal, 2300-2800 m, 13.V.1962, G. EBERT leg., 1 Ex.

Bisher aus Indien und Burma bekannt (KAPUR 1951), neu für die Fauna Nepals.

An der Basis des Pronotums jederseits des Scutellums kleine Fleckehen. Alle vier Flecke jeder Flügeldecke miteinander verknüpft (Abb. 30).

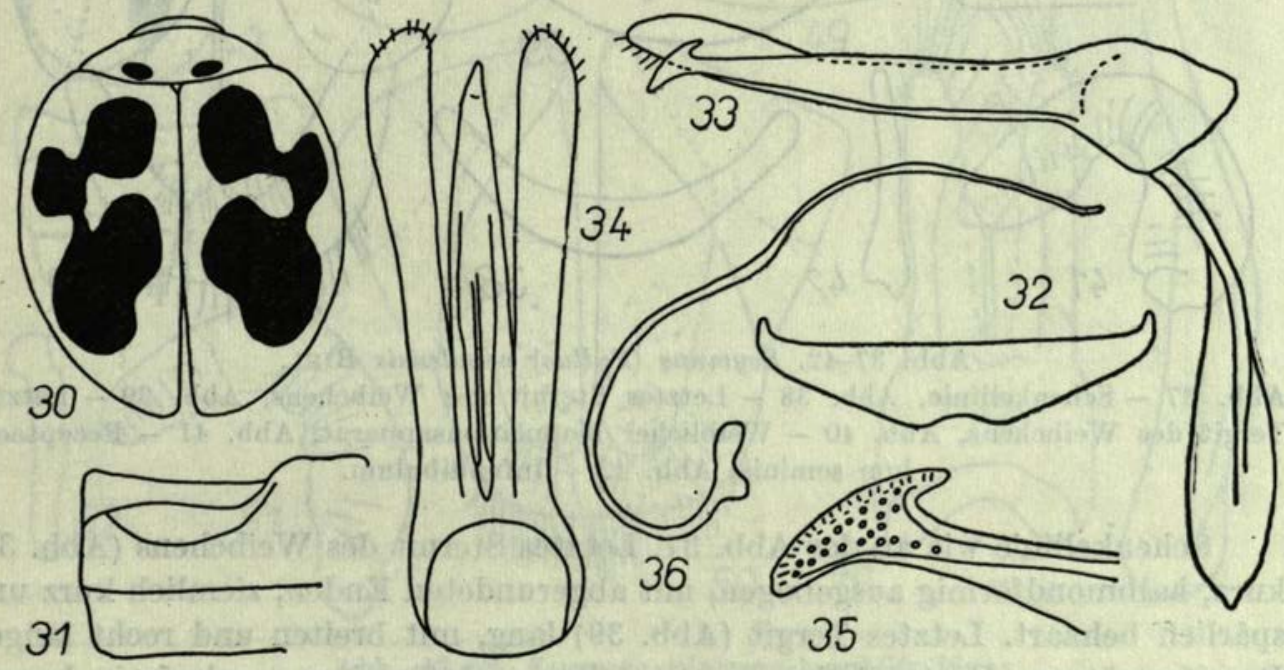

Abb. 30-36. Rodolia octoguttata Ws.

Abb. 30 - Körperumriss, Abb. 31 - Schenkellinie, Abb. 32 - Letztes Sternit des Männchens, Abb. 33 und 34 - Kopulationsapparat des Männchens, Abb. 35 - Ende des Siphos von der Seite, Abb. 36 - Sipho. 
Schenkellinie (Abb. 31) vollständig, in Form eines sanften Bogens, mit der Ausbiegung fast bis zur halben Segmentlänge reichend. Letztes Sternit des Männchens (Abb. 32) kurz, mit unmerklichem Einschnitt in der Mitte des Hinterrandes. Letztes Tergit lang, kurz behaart, mit sehr kurzen und breiten Basalfortsätzen.

Männlicher Kopulationsapparat (Abb. 33-34). Penis kaum kürzer als die Parameren, 0,85 mm lang, höchstens $0,1 \mathrm{~mm}$ breit. Penisspitze (Abb. 35) mit hakenförmigem Fortsatz von der Seite der Parameren. Sipho (Abb. 36) schlank, lang, mit kleiner Kapsel.

\section{Scymnus (Pullus) nepalensis BrEL.}

Untersuchtes Material: Tampa Khosi Tal, $2600 \mathrm{~m}, 10 . \mathrm{V} .1962$, G. EBert leg., 1 Ex.; Jiri, $1900 \mathrm{~m}$, 17.-19.V.1962, G. EBert leg., 1 Ex.

Die Art wurde von mir (BIELAWsKI 1970) aus Nepal beschrieben.

Die vorliegenden Exemplare (Weibchen) haben Kopf, Seiten- und Vorderrand des Pronotums, Beine und Ende der Flügeldecken bräunlich. Geschlechtsdimorphismus kommt hier in der Körperfärbung nicht vor.

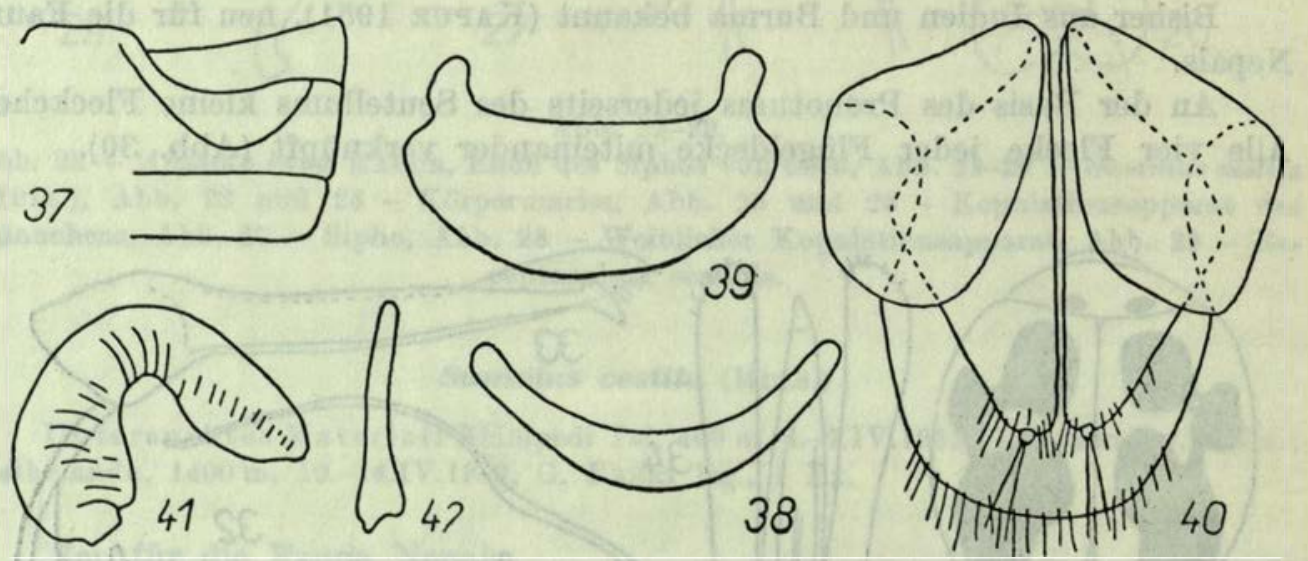

Abb. 37-42. Scymnus (Pullus) nepalensis BIEL.

Abb. 37 - Schenkellinie, Abb. 38 - Letztes Sternit des Weibchens, Abb. 39 - Letztes Tergit des Weibchens, Abb. 40 - Weiblicher Kopulationsapparat, Abb. 41 - Receptaculum seminis, Abb. 42 - Infundibulum.

Schenkellinie wie an der Abb. 37. Letztes Sternit des Weibchens (Abb. 38) kurz, halbmondförmig ausgebogen, mit abgerundeten Enden, ziemlich kurz und spärlich behaart. Letztes Tergit (Abb. 39) lang, mit breiten und recht langen Basalfortsätzen. Hinterränder des Sternites und Tergites regelmässig bogenförmig ausgebogen.

Weiblicher Kopulationsapparat (Abb. 40). Genitalplatten am breitesten fast in ihrer halben Länge. Geschlechtshügel gross. Behaarung spärlich. 
Länge der Genitalplatte $0,35 \mathrm{~mm}$, grösste Breite $0,2 \mathrm{~mm}$. Receptaculum seminis (Abb. 41) massiv, in Form eines stark ausgebogenen Hörnchens. Infundibulum (Abb. 42) schwach sklerotisiert, schmal.

\section{Scymnus (Scymnus) nubilis MuLs.}

Untersuchtes Material: Rapti Tal, $300 \mathrm{~m}$, Megouli, 1.IV.1962, G. EBert leg., 2 Ex.; Kathmandu Valley, Godavari, 1600 m, 31.V.1964, LöfrLer leg., 1 Ex.

Bisher bekannt aus Indien und Burma, letztens auch aus Kleinasien gemeldet (GÜNTER 1958). Erstfunde in Nepal.

Die vorliegenden Stücke sind identisch gefärbt (Abb. 43) wie die Exemplare der Art aus Indien.

Schenkellinie (Abb. 44) unvollständig, mit ihrer Ausbiegung bis $3 / 4$ der Segmentlänge reichend. Letztes Sternit bei dem Männchen (Abb. 45) mit geradem Hinterrand, bei dem Weibchen (Abb. 46) recht lang, mit regelmässig bogenförmigem Hinterrand.

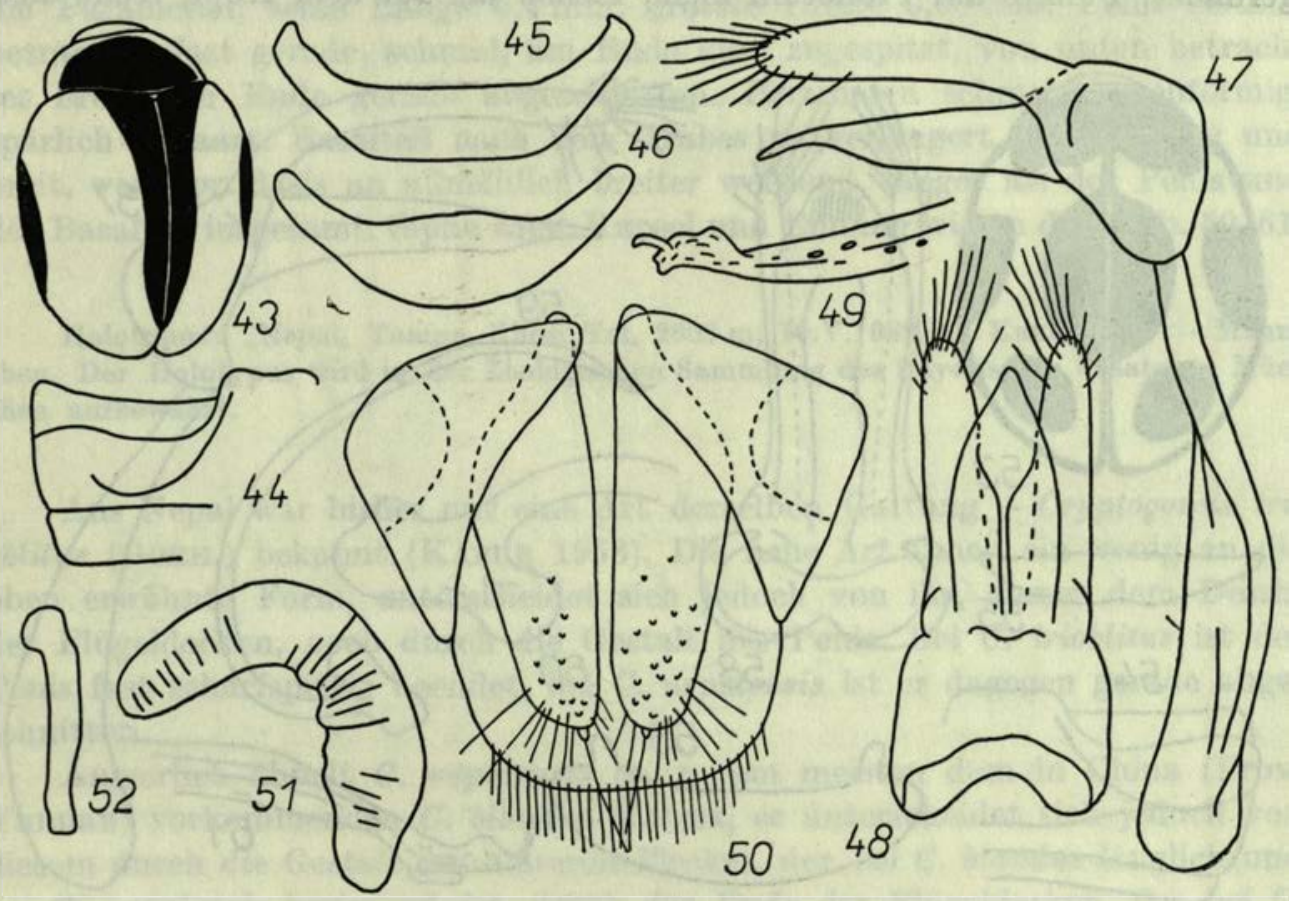

Abb. 43-52. Scymnus (Scymnus) nubilis Muls.

Abb. 43 - Körperumriss, Abb. 44 - Schenkellinie, Abb. 45 - Letztes Sternit des Männchens, Abb. 46 - Letztes Sternit des Weibchens, Abb. 47 und 48 - Kopulationsapparat des Männchens, Abb. 49 - Ende des Siphos von der Seite, Abb. 50 - Weiblicher Kopulationsapparat, Abb. 51 - Receptaculum seminis, Abb. 52 - Infundibulum. 
Männlicher Kopulationsapparat (Abb. 47-48). Penis so lang wie die Parameren, seine Länge $0,2 \mathrm{~mm}$, grösste Breite $0,05 \mathrm{~mm}$. Penis seitlich betrachtet fast gerade, am Ende kurz zugespitzt, von unten betrachtet in seiner halben Länge am breitesten. Parameren breit, fast gerade, knapp behaart. Basalteil nach dem Trabes zu verlängert. Trabes breit und sehr lang. Sipho in hinterer Hälfte halbkreisförmig ausgebogen, mit grosser Kapsel. Siphoendung wie an der Abb. 49.

Weiblicher Kopulationsapparat (Abb. 50). Länge der Genitalplatten $0,26 \mathrm{~mm}$, grösste Breite $0,07 \mathrm{~mm}$. Haare lang und zahlreich. Receptaculum seminis und Infundibulum wie an den Abb. 51 und 52.

\section{Cryptogonus nepalensis sp. $\mathrm{n}$.}

Körper breit oval, schwach gewölbt. Kopf gelb, Mundanhänge dunkelbraun. Punkte auf dem Kopf gross und sehr dicht angeordnet. Pronotum schwarz mit gelblichen vorderen $2 / 3$ der Seitenränder und sehr schmal gelblich umsäumtem Vorderrand. Seitenränder gerade, Vorderwinkel schwach abgerundet. Punkte auf Pronotum klein, kleiner als auf dem Kopf, recht dicht
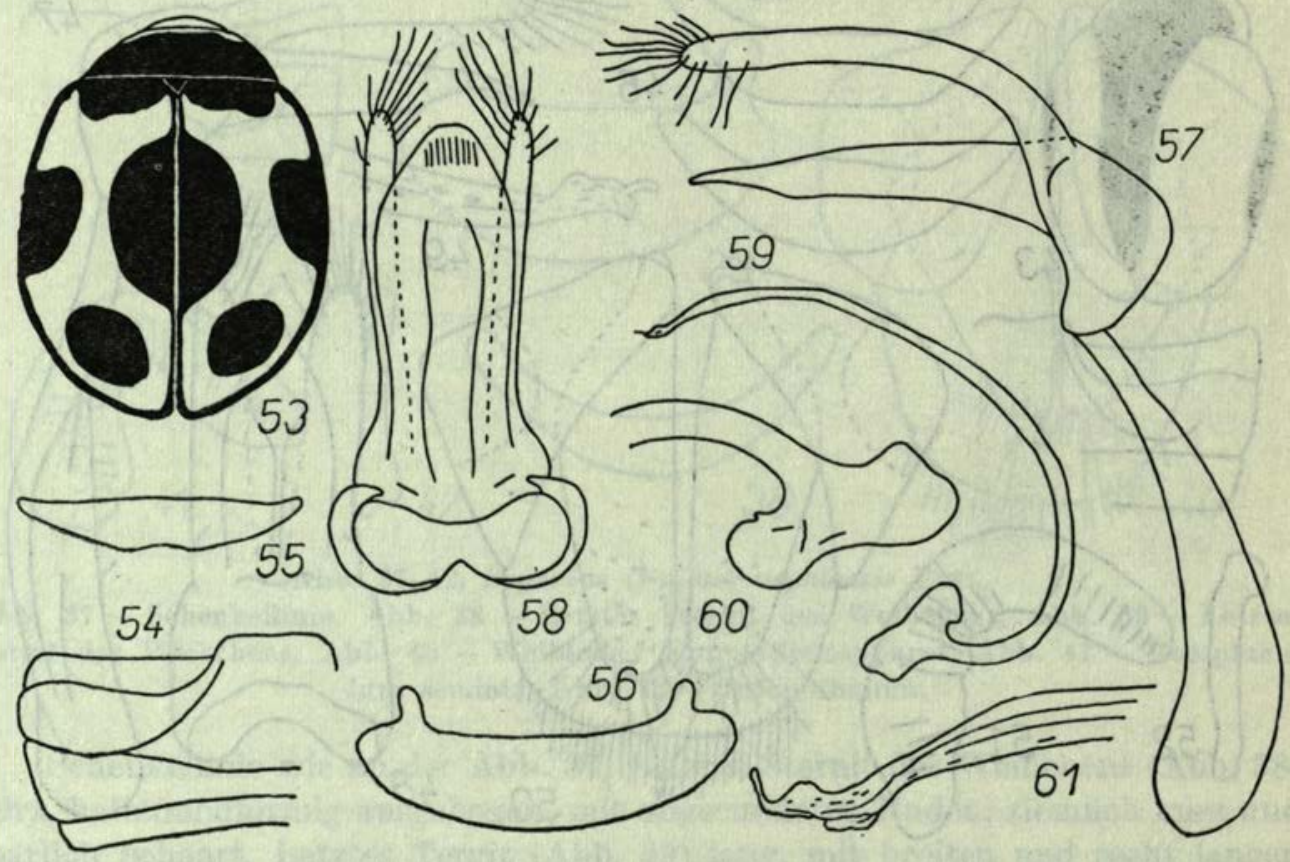

Abb. 53-61. Cryptogonus nepalensis sp. n.

Abb. 53 - Körperumriss, Abb. 54 - Schenkellinie, Abb. 55 - Letztes Sternit des Männchens, Abb. 56 - Letztes Tergit des Männchens, Abb. 57 und 58 - Kopulationsapparat des Männchens, Abb. 59 - Sipho, Abb. 60 - Siphokapsel, Abb. 61 - Ende des Siphos von der Seite. 
angeordnet, so dass die Abstände zwischen ihnen kleiner als die Durchmesser der Punkte sind. Die Flächen zwischen den Punkten glatt. Scutellum stark verlängert, schwarz. Flügeldecken dunkelgelb mit schwarzem Dessin - wie an der Abb. 53. Schulterbeulen gross, schwach herausstehend. Haare goldig, lang, anliegend. Punkte auf den Flügeldecken recht gross, Abstände zwischen ihnen etwas grösser als ihre Durchmesser. Die Flächen zwischen den Punkten glatt.

Unterfläche des Körpers schwarz. Epipleuren der Flügeldecken und des Pronotums bräunlich. Schenkel schwarz, mit bräunlichen distalen Enden. Schienen bräunlich. Rippen auf Prosternum den Vorderrand nicht erreichend und miteinander bogenförmig verknüpfend - ähnlich wie bei $C$. orbicularis (GYLL.). Schenkellinie (Abb. 54) in Form eines sanften Bogens den Hinterrand erreichend. Letztes Sternit des Männchens (Abb. 55) mit kaam eingeschnittenem Hinterrand. Letztes Tergit (Abb. 56) mit kurzen und schmalen Basalfortsätzen.

Körperlänge $3,2 \mathrm{~mm}$, grösste Breite $2,7 \mathrm{~mm}$.

Männlicher Kopulationsapparat (Abb. 57-58). Penis gleich lang wie die Parameren, seine Länge $0,4 \mathrm{~mm}$, grösste Breite $0,08 \mathrm{~mm}$. Penis seitlich betrachtet fast gerade, schmal, am Ende kurz zugespitzt, von unten betrachtet breit, am Ende gerade abgeschnitten. Parameren schmal, bogenförmig, spärlich behaart. Basalteil nach dem Trabes zu verlängert. Trabes lang und breit, von der Basis an allmählich breiter werdend, länger als der Penis und der Basalteil insgesamt. Sipho samt Kapsel und Endung wie an den Abb. 59-61.

Holotypus: „Nepal, Tampa Khosi Tal, 2600 m, 10.V.1962, G. EвERT leg.” - Männchen. Der Holotypus wird in der Zoologischen Sammlung des Bayerischen Staates in München aufbewahrt.

Aus Nepal war bisher nur eine Art derselben Gattung - Cryptogonus trioblitus (GoRH.) bekannt (KAPUR 1958), Die neue Art ähnelt ein wenig an die oben erwähnte Form, unterscheidet sich jedoch von ihr, ausser dem Dessin der Flügeldecken, noch durch die Gestalt des Penis. Bei $C$. trioblitus ist der Penis fast scharfspitzig beendet, bei $C$. nepalensis ist er dagegen gerade abgeschnitten.

Äusserlich ähnelt $C$. nepalensis sp. n. am meisten dem in China (Prov. Yunnan) vorkommenden $C$. blandus MADER, er unterscheidet sich jedoch von diesem durch die Gestalt des hinteren Fleckes, der bei $C$. blandus länglich und bei $C$. nepalensis kreisrund ist, durch das Ende der Flügeldecken, das bei $C$. blandus breit und bei der neuen Art sehr schmal schwarz angelaufen ist, sowie durch die Färbung des vorderen Teiles der Flügeldecken - bei $C$. blandus gibt es dort einen Fleck und bei $C$. nepalensis ist kein Fleck vorhanden, nur der schwarze Saum des Vorderrandes ist stark erweitert. 


\section{Jauravia limbata Мотsсн.}

Untersuchtes Material: Sun Khosi Tal, 2150 m, 2.V.1962, G. EBert leg., 2 Ex.

Die Art wurde bisher von Indien und Ceylon bekannt und wird zum ersten Mal für Nepal nachgewiesen. Manche Autoren (WEISE 1908, KoRSCHEFSKY 1931) reihten sie in die Gattung Sticholotis Cr. ein. Das Problem der Gattungsangehörigkeit wurde von KAPUR (1946) aufgeklärt. Der männliche Kopulationsapparat wurde ebenda beschrieben.

Kopf, Pronotum, Scutellum und seitliches Drittel der Flügeldecken rostrot. Diskus der Flügeldecken schwarz (Abb, 62).

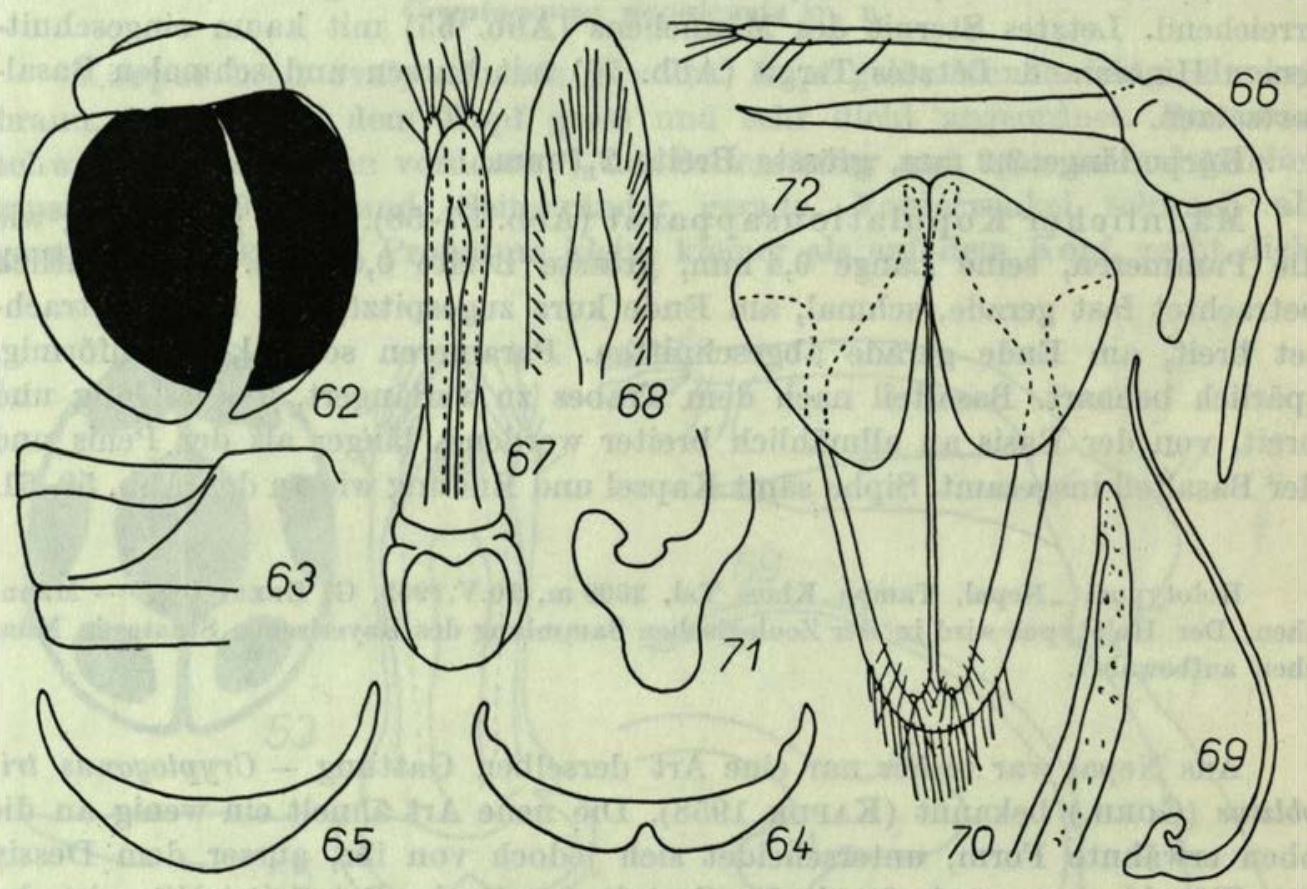

Abb. 62-72. Jauravia limbata Mотsch.

Abb. 62 - Körperumriss, Abb. 63 - Schenkellinie, Abb. 64 - Letztes Sternit des Männchens, Abb. 65 - Letztes Sternit des Weibchens, Abb. 66 und 67 - Kopulationsapparat des Männchens, Abb. 68 - Penisende, Abb. 69 - Sipho, Abb. 70 - Ende des Siphos von der Seite, Abb. 71 - Siphokapsel, Abb, 72 - Weiblicher Kopulationsapparat.

Schenkellinie unvollständig (Abb. 63). Letztes Sternit des Männchens (Abb. 64) stark halbkreisförmig verbogen mit tiefem Einschnitt mitten im Hinterrande. Letztes Tergit mit schmalen und sehr langen Basalfortsätzen. Letztes Sternit des Weibchens (Abb. 65) mit schmalen und länglichen Seitenteilen, schwach ausgebogen. 
Männlicher Kopulationsapparat wurde an den Abb. 66-71 dargestellt. Länge des Penis $0,55 \mathrm{~mm}$, grösste Breite $0,06 \mathrm{~mm}$. Weiblicher Kopulationsapparat wie an der Abb. 72. Länge der Genitalplatte $0,57 \mathrm{~mm}$, grösste Breite $0,13 \mathrm{~mm}$.

\section{Jauravia quadrinotata KAPUR}

Untersuchtes Material: Bhimpedi Tal, $400 \mathrm{~m}$, 4.-7.IV.1962, G. EBert leg., 1 Ex.

Bisher nur aus Indien bekannt (KAPUR 1946), neu für die Fauna Nepals.

Die Art hat ein sehr charakteristisches Dessin der Flügeldecken, und zwar auf jeder Decke je zwei hintereinander gelegene schwarze Flecke.

\section{Chilocomus rubidus HoPE}

Untersuchtes Material: Ting-Sang-La, $3800 \mathrm{~m}, 6 .-7 . V .1962$, G. EBert leg., 1 Ex.

Die Art wurde aus Nepal beschrieben und ist sehr weit verbreitet: Japan, Korea, Mandschurei, Sibirien, Mongolei, China, Nepal, Indien, Celebes und Australien. Letztens wieder von Nepal von KAPUR (1958) gemeldet.

\section{Chilocorus politus MuLs.}

Untersuchtes Material: Indrawati Khola, Saretar, 25.-26.IV.1962, $1700 \mathrm{~m}$, G. Ebert leg., 1 Ex.

Bekannt aus Nepal, Indien und Java. Für Nepal von CrotcH (1874) nachgewiesen.

Die besprochene Art ist von Ch. rubidus Hope sofort $\mathrm{zu}$ unterscheiden, und zwar durch die Färbung - der Körper ist bei ihr rostrot, während bei Ch. rubidus Kopf, Pronotum und Ränder der Flügeldecken schwarz sind.

\section{Exochomus himalayensis KAPUR}

Untersuchtes Material: Thodung, Prov. Nr. 2 East, $3200 \mathrm{~m}, 14 .-21 . I V .1964$, W. DIERL leg., 2 Ex.

Von KAPUR (1958) aus Nepal beschrieben. Bei beiden vorliegenden Exemplaren sind die suturale und die diskale Binde miteinander verknüpft (Abb. 73).

Schenkellinie (Abb. 74) unvollständig, mit ihrer Ausbiegung bis $2 / 3$ der Segmentlänge reichend. Letztes Sternit des Männchens (Abb. 75) kurz, mit seicht eingeschnittenem Hinterrand. Letztes Tergit des Männchens recht lang, mit sehr kurzen und breiten Basalfortsätzen. Letztes Sternit des Weibchens (Abb. 76) mit deutlich verlängerten Seitenrändern und regelmässig. bogenför- 
mig ausgebogenem Hinterrand. Letztes Tergit des Weibchens lang, mit schmalen Basalfortsätzen.

Männlicher Kopulationsapparat (Abb. 77-78). Penis kürzer als die Parameren, 0,35 mm lang, höchstens $0,08 \mathrm{~mm}$ breit, seitlich betrachtet gerade,

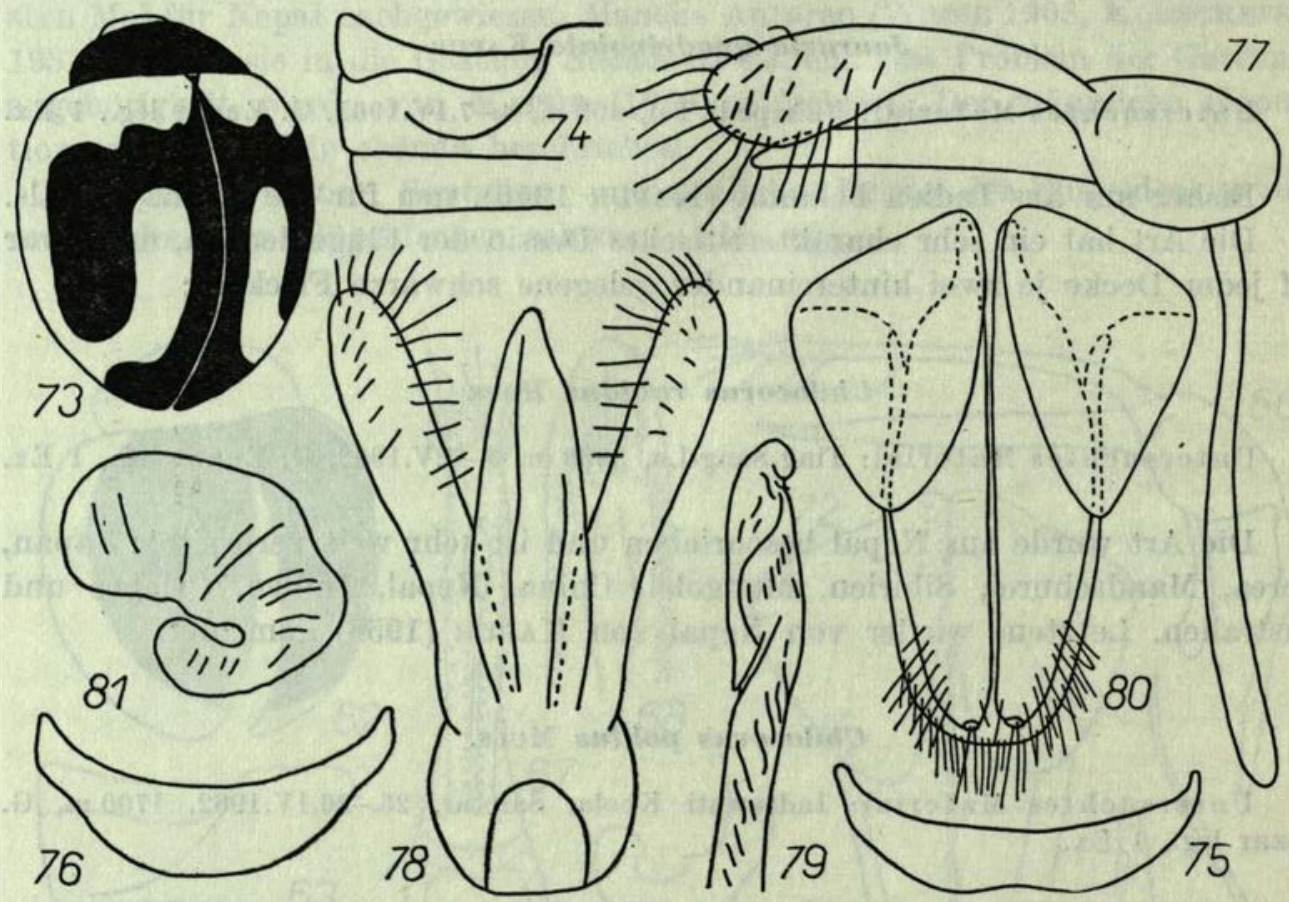

Abb. 73-81. Exochomus himalayensis KAPUR.

Abb. 73 - Körperumriss, Abb. 74 - Schenkellinie, Abb. 75 - Letztes Sternit des Männchens, Abb. 76 - Letztes Sternit des Weibchens, Abb. 77 und 78 - Kopulationsapparat des Männchens, Abb. 79 - Ende des Siphos von der Seite, Abb. 80 - Weiblicher Kopulationsapparat, Abb. 81 - Receptaculum seminis.

am Ende abgerundet. Parameren von der Basis an bis zur halben Länge schmal dann stark in eine Keule erweitert, lang und reichlich behaart. Basalteil oval Trabes lang und schmal, fast gleich lang wie die Parameren samt Basalteil. Siphoendung wie an der Abb. 79.

Weiblicher Kopulationsapparat (Abb. 80). Genitalplatte $0,7 \mathrm{~mm}$ lang, höchstens $0,15 \mathrm{~mm}$ breit, reichlich und recht lang behaart. Receptaculum seminis wie an der Abb. 81 .

\section{Brumus suturalis (F.)}

Untersuchtes Material: Rapti Tal, $300 \mathrm{~m}$, 27.III.1962, G. EBERT leg., 1 Ex.; Rapti Tal, 300 m, Megouli, 1.IV.1962, G. EBert leg., 2 Ex.; Jubing, Prov. Nr. 3 East, 1600 m, 2.V.1964, W. DierL leg., 1 Ex. 
Bisher aus Indien, Ceylon und Himalaja bekannt, neu für die Fauna Nepals.

Alle vorliegenden Exemplare sind identisch gefärbt und identisch mit den Individuen aus Indien. Auf jeder Flügeldecke kommen je zwei Längsbinden vor, die jedoch keinen Rand der Flügeldecke erreichen (Abb. 82). Naht breit schwarz gefärbt, diese Farbe erreicht jedoch nicht das Ende der Flügeldecken.

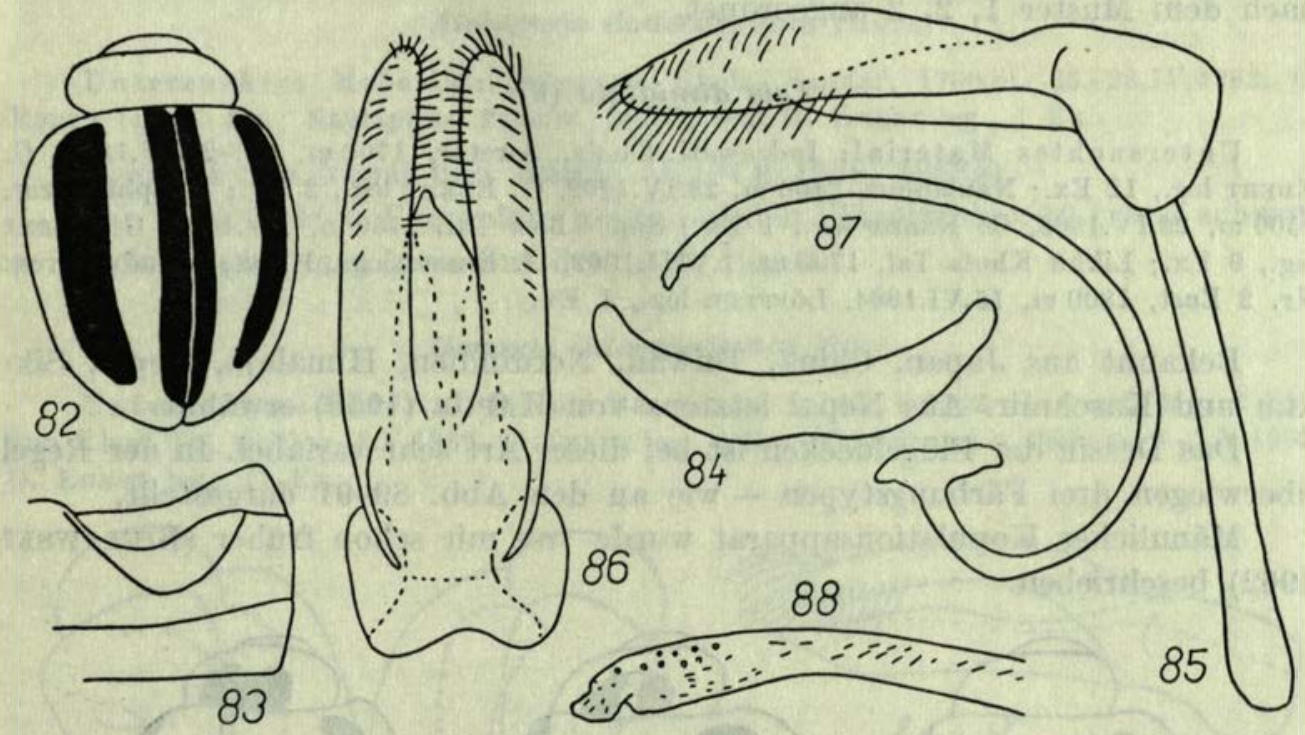

Abb. 82-88. Brumus suturalis (F.).

Abb. 82 - Körperumriss, Abb. 83 - Schenkellinie, Abb. 84 - Letztes Sternit des Männchens, Abb. 85 und 86 - Kopulationsapparat des Männchens, Abb. 87 - Sipho, Abb. 88 Ende des Siphos von der Seite.

Schenkellinie vollständig (Abb. 83), mit ihrer Ausbiegung bis $2 / 3$ der Segmentlänge reichend. Letztes Sternit des Männchens (Abb. 84) mit unmerklich eingeschnittenem Hinterrand. Letztes Sternit des Weibchens recht lang, mit regelmässig bogenförmig ausgebogenem Hinterrand, an den Seiten fast gerade abgeschnitten.

Männlicher Kopulationsapparat (Abb. 85-86). Penis kaum länger als $2 / 3$ der Parameren, $0,35 \mathrm{~mm}$ lang, höchstens $0,1 \mathrm{~mm}$ breit, seitlich betrachtet fast gerade, spitzig beendet, von unten betrachtet von der Basis an allmählich verjüngend, am Ende, an der linken Seite asymmetrisch ausgeschnitten. Parameren gerade, breit, am breitesten in $2 / 3$ ihrer Länge, recht kurz behaart. Basalteil dem Trabes zu verlängert. Trabes gerade, auf der ganzen Länge fast gleich breit, kaum kürzer als die Parameren samt Basalteil. Sipho (Abb. 87) halbkreisförmig verbogen, mit grosser Kapsel. Siphoendung wie an der Abb. 88 .

Die Gestalt der Genitalplatte wurde von mir schon früher (BIELAwSKI 1957) beschrieben. 


\section{Anisolemnia dilatata (F.)}

Untersuchtes Material: Bi Khola Tal, 2300-2800 m, 13.V.1962, G. Ebert leg., 1 Ex.

Eine weit verbreitete Art: Indien, China, Mandschurei, Sumatra, Borneo, Java, neu für die Fauna Nepals.

Das vorliegende Exemplar hat an der Basis des Pronotums zwei kleine schwarze Fleckchen. Scutellum schwarz. Auf jeder Flügeldecke je fünf Flecke, nach dem Muster 1, 2, 2 angeordnet.

\section{Leis dimidiata (F.)}

Untersuchtes Material: Indrawati Khola, Saretar, $1700 \mathrm{~m}, 25 .-26 . I V .1962, \mathrm{G}$. Ebert leg., 12 Ex.; Naulaphur, 2400 m, 28.IV.1962, G. EBert leg., 2 Ex.; Belephi Bazar, 1500 m, 29.IV.1962, G. Ebert leg., 1 Ex.; Sun Khosi Tal, 2150 m, 2.V.1962, G. EberT leg., 9 Ex.; Likhu Khola Tal, 1700 m, 1.VIII.1962, G. EвERT leg., 1 Ex.; Namdu, Prov. Nr. 2 East, $1800 \mathrm{~m}$, 15.VI.1964, LöFFLER leg., 1 Ex.

Bekannt aus Japan, China, Taiwan, Nordindien, Himalaja, Nepal, Sikkim und Kaschmir. Aus Nepal letztens von KAPUR (1958) erwähnt.

Das Dessin der Flügeldecken ist bei dieser Art sehr variabel. In der Regel überwiegen drei Färbungstypen - wie an den Abb. 89-91 dargestellt.

Männlicher Kopulationsapparat wurde von mir schon früher (BIELAWsKI 1962) beschrieben.
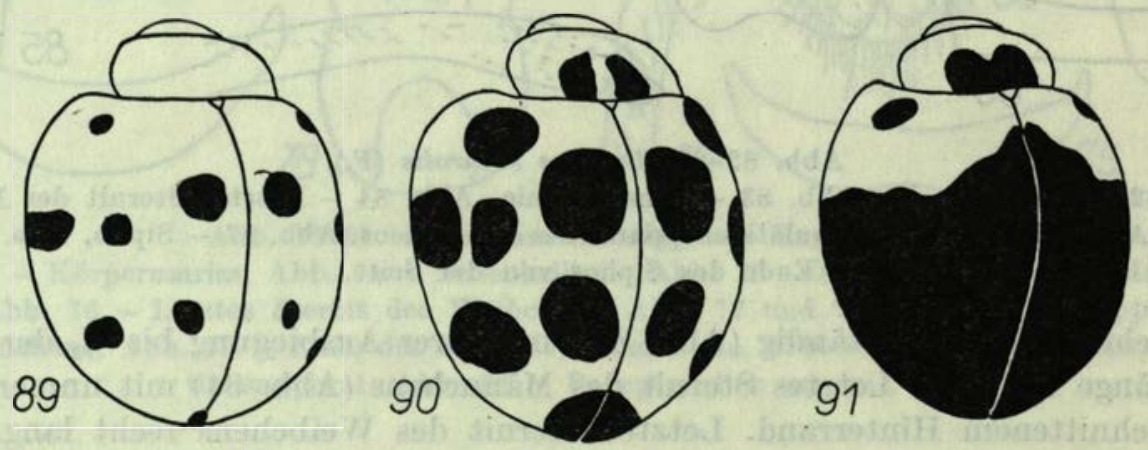

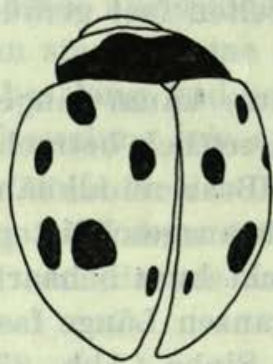

92
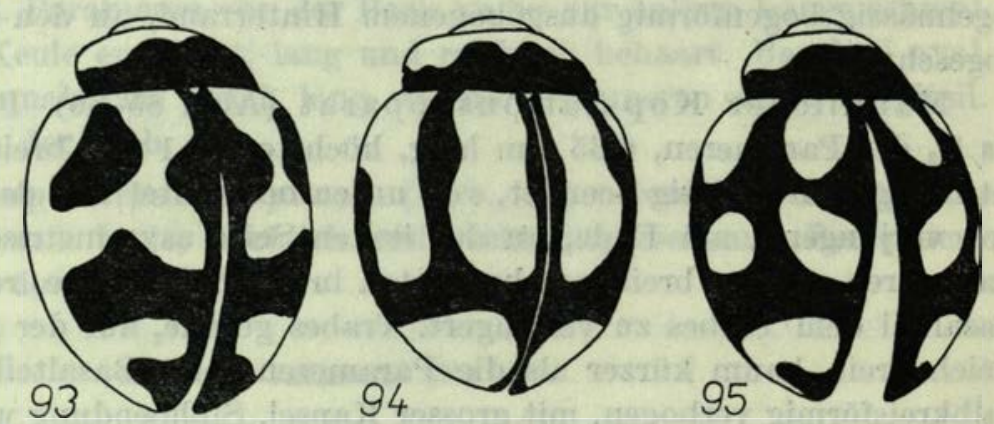

Abb. 89-95. Körperumriss.

Abb. 89-91 - Leis dimidiata (F.), Abb. 92-95 - Oenopia luteopustulata Muls. 


\section{Aiolocaria hexaspilota (HOPE)}

Untersuchtes Material: Kimpti Kola, 2000 m, 31.X.1961, Gruber leg., 1 Ex.

Bekannt aus Kaschmir, Sikkim, Nepal und Burma (KAPUR 1958).

Das vorliegende Exemplar hat auf jeder Flügeldecke je drei schwarze Flecke und die vordere Hälfte der Naht ist ebenfalls schwarz.

\section{Aiolocaria dodecaspilota (HopE)}

Untersuchtes Material: Indrawati Khola, Saretar, $1700 \mathrm{~m}$, 25.-28.IV.1962, G. EвеRт leg., 1 Ex.; Naulaphur, 2400 m, 28.IV.1962, G. EвеRт leg., 1 Ex.

Bekannt aus Nepal und Burma (KAPUR 1958, 1963a).

Die untersuchten Exemplare haben auf den Flügeldecken 10 grosse schwarze Flecke, von denen zwei auf der Naht liegen.

\section{Oenopia luteopustulata Muls.}

Untersuchtes Material: Belephi Bazar, 1500 m, 29.IV.1962, G. EBert leg., 2 Ex.; Sun Khosi Tal, 2150 m, 2.V.1962, G. EBert leg., 6 Ex.; Ting-Sang-La, 3800 m, 6.-7.V.1962, G. Ebert leg., 11 Ex.

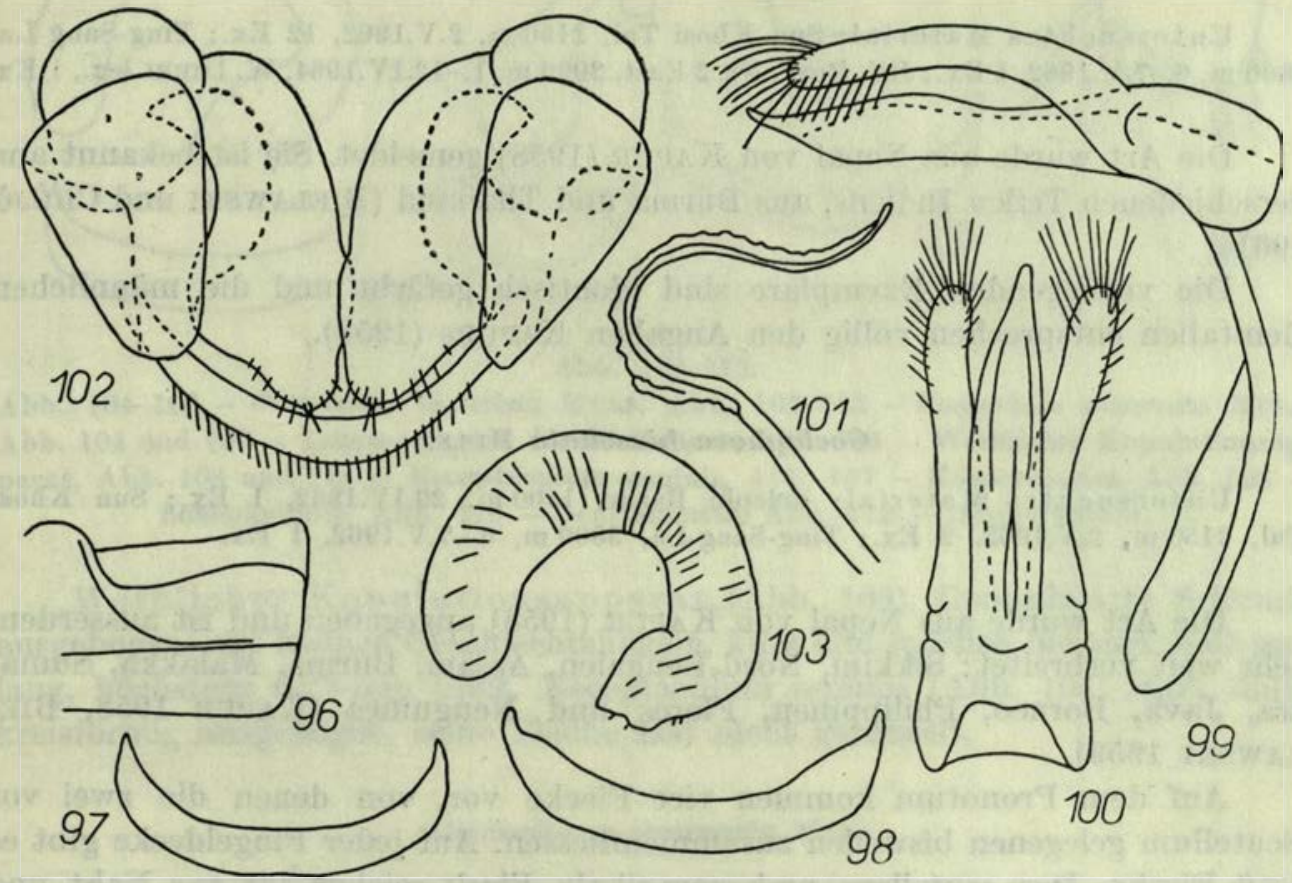

Abb. 96-103. Oenopia luteopustulata McLs.

Abb. 96 - Schenkellinie, Abb. 97 - Letztes Sternit des Männehens, Abb. 98 - Letztes Stercit des Weibchens, Abb. 99 und 100 - Kopulationsapparat des Männchens, Abb. 101 Ende des Siphos von der Seite, Abb. 102 - Weiblicher Kopulationsapparat, Abb. 103 Receptaculum seminis. 
Eine weit verbreitete Art: Burma, Nordindien, Himalaja, Nepal, Tibet. Aus Nepal letztens von KAPUR (1958) gemeldet.

Dessin der Flügeldecken sehr variabel - siehe Abb. 92-95.

Schenkellinie (Abb. 96) unvollständig, mit ihrer Ausbiegung fast den Hinterrand erreichend und weiter parallel $\mathrm{zu}$ ihm verlaufend. Letztes Sternit des Männchens (Abb. 97) kurz, halbmondförmig ausgebogen, sein Hinterrand ohne Ausschnitt. Letztes Sternit des Weibchens (Abb. 98) kaum ausgebogen, kurz.

Männlicher Kopulationsapparat (Abb. 99-100). Penis länger als die Parameren, 0,74-0,83 mm lang, höchstens 0,11-0,15 mm breit. Parameren deutlich bogenförmig ausgebogen, nicht allzu lang aber reichlich behaart. Basalteil unmerklich verlängert. Trabes kürzer als der Penis samt Basalteil. Sipho schlank, mit kleiner Kapsel, beendet wie an der Abb. 101.

Weiblicher Kopulationsapparat (Abb. 102). Genitalplatte $0,64 \mathrm{~mm}$ lang, höchstens $0,28 \mathrm{~mm}$ breit. Geschlechtshügel sehr klein, Behaarung kurz und spärlich. Receptaculum seminis (Abb. 103) halbkreisförmig verbogen, nicht differenziert.

\section{Oenopia sauzeti MuLs.}

Untersuchtes Material: Sun Khosi Tal, $2150 \mathrm{~m}, 2 . \mathrm{V} .1962,12 \mathrm{Ex}$.; Ting-Sang-La 3800 m, 6.-7.V.1962, 1 Ex.; Jiri, Prov. Nr. 2 East, 2000 m, 1.-12.IV.1964, W. DierL leg., 1 E x

Die Art wurde aus Nepal von KAPUR (1958) gemeldet. Sie ist bekannt aus verschiedenen Teilen Indiens, aus Burma und Thailand (BIELAwSKI und CHÛJô 1961).

Die vorliegenden Exemplare sind identisch gefärbt und die männlichen Genitalien entsprechen völlig den Angaben KAPURs (1958).

\section{Coelophora bissellata MuLs.}

Untersuchtes Material: Belephi Bazar, $1500 \mathrm{~m}$, 29.IV.1962, 1 Ex.; Sun Khosi Tal, 2150 m, 2.V.1962, 2 Ex.; Ting-Sang-La, $3800 \mathrm{~m}, 6 .-7 . V .1962,1$ Ex.

Die Art wurde aus Nepal von KAPUR (1958) angegeben und ist ausserdem sehr weit verbreitet: Sikkim, Nord-Bengalen, Assam, Burma, Malakka, Sumatra, Java, Borneo, Philippinen, Flores und Neuguinea (KAPUR 1958, BIELAWSKI 1959).

Auf dem Pronotum kommen vier Flecke vor, von denen die zwei vor Scutellum gelegenen bisweilen zusammenfliessen. Auf jeder Flügeldecke gibt es je 6 Flecke. Der scutellare und vorapikale Fleck reichen bis zur Naht und verknüpfen mit den gegenüber liegenden Flecken. Der vordere, am Seitenrand gelegene Fleck erreicht die Kante der Flügeldecke.

Männlicher Kopulationsapparat stimmt mit meinen früheren Angaben (BIELAWSKI 1959) überein. 
Letztes Sternit des Weibchens (Abb. 104) sehr kurz, unmerklich bogenförmig ausgebogen, kurz und spärlich behaart. Letztes Tergit des Weibchens mit sehr kurzen und schmalen Basalfortsätzen, regelmässig bogenförmigem Hinterrand, kurz und spärlich behaart. Die Haare auf dem Tergit und Sternit sitzen in gewissem Abstand von dem Rande.

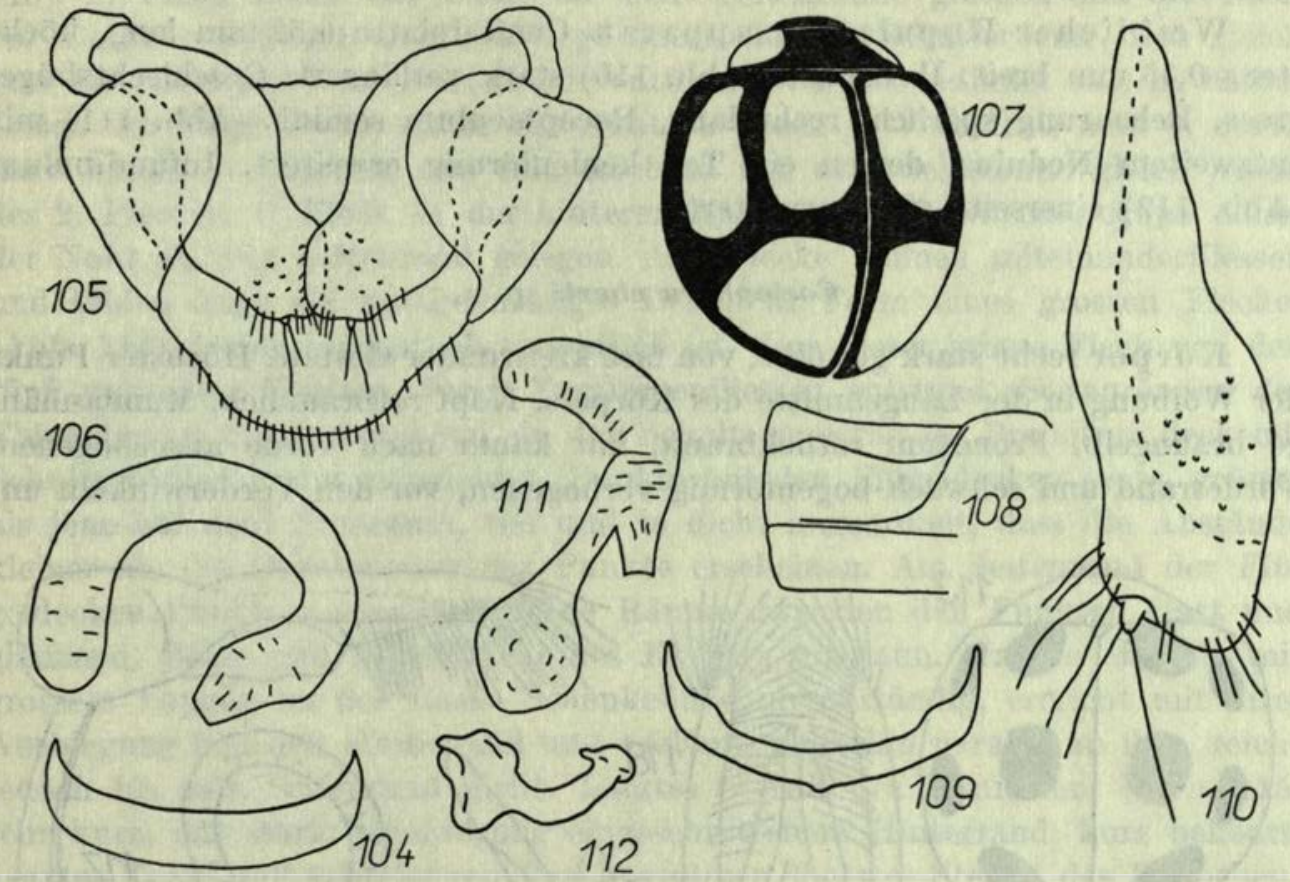

Abb. 104-112.

Abb. 104-106 - Coelophora bissellata Muls. Abb. 107-112-Coelophora sexareata Muls. Abb. 104 und 109 - Letztes Sternit des Weibchens, Abb. 105 - Weiblicher Kopulationsapparat, Abb. 106 und 111 - Receptaculum seminis, Abb. 107 - Körperumriss, Abb. 108 Schenkellinie, Abb. 110 - Genitalplatte, Abb. 112 - Infundibulum.

Weiblicher Kopulationsapparat (Abb. 105). Genitalplatte S-förmig ausgebogen, mit kleinen Geschlechtshügeln, kurz und spärlich behaart, $0,65 \mathrm{~mm}$ lang, höchstens $0,25 \mathrm{~mm}$ breit. Receptaculum seminis (Abb. 106) stark halbkreisförmig ausgebogen, seine Fläche fast nicht gerunzelt.

\section{Coelophora sexareata MuLs.}

Untersuchtes Material: Ting-Sang-La, 3800 m, 6.-7.V.1962, G. EBERT leg., 1 Ex.

Die Art ist aus Nepal, Sikkim, Indien, Burma und West-Yunnan bekannt.

Das Dessin der Flügeldecken ist hier sehr charakteristisch - auf jeder Decke kommen drei grosse gelbliche Flecke vor (Abb. 107). 
Schenkellinie (Abb. 108) unvollständig, mit ihrer Ausbiegung fast den Hinterrand erreichend und parallel $\mathrm{zu}$ ihm verlaufend. Letztes Sternit des Weibchens (Abb. 109) sehr kurz, sein Hinterrand in der Mitte unmerklich ausgebogen, Basalfortsätze lang und schmal. Letztes Tergit des Weibchens lang, sein Hinterrand in der Mitte unmerklich geknickt, Basalfortsätze kurz und recht schmal.

Weiblicher Kopulationsapparat. Genitalplatte 0,52 $\mathrm{mm}$ lang, höchstens $0,15 \mathrm{~mm}$ breit. Ihre Basis (Abb. 110) stark verlängert. Geschlechtshügel gross. Behaarung spärlich, recht lang. Receptaculum seminis (Abb. 111) mit entzweitem Nodulus, dessen ein Teil keulenförmig erweitert. Infundibulum (Abb. 112) einerseits stark erweitert.

\section{Coelophora eberti sp. n.}

Körper recht stark gewölbt, von fast kreisrunder Gestalt. Höchster Punkt der Wölbung in der Längenmitte des Körpers. Kopf rotbräunlich, Mundanhänge braungelb. Pronotum rötlichbraun, mit kaum nach vorne ausgebogenem Vorderrand und schwach bogenförmig verbogenen, vor den Vorderwinkeln un-

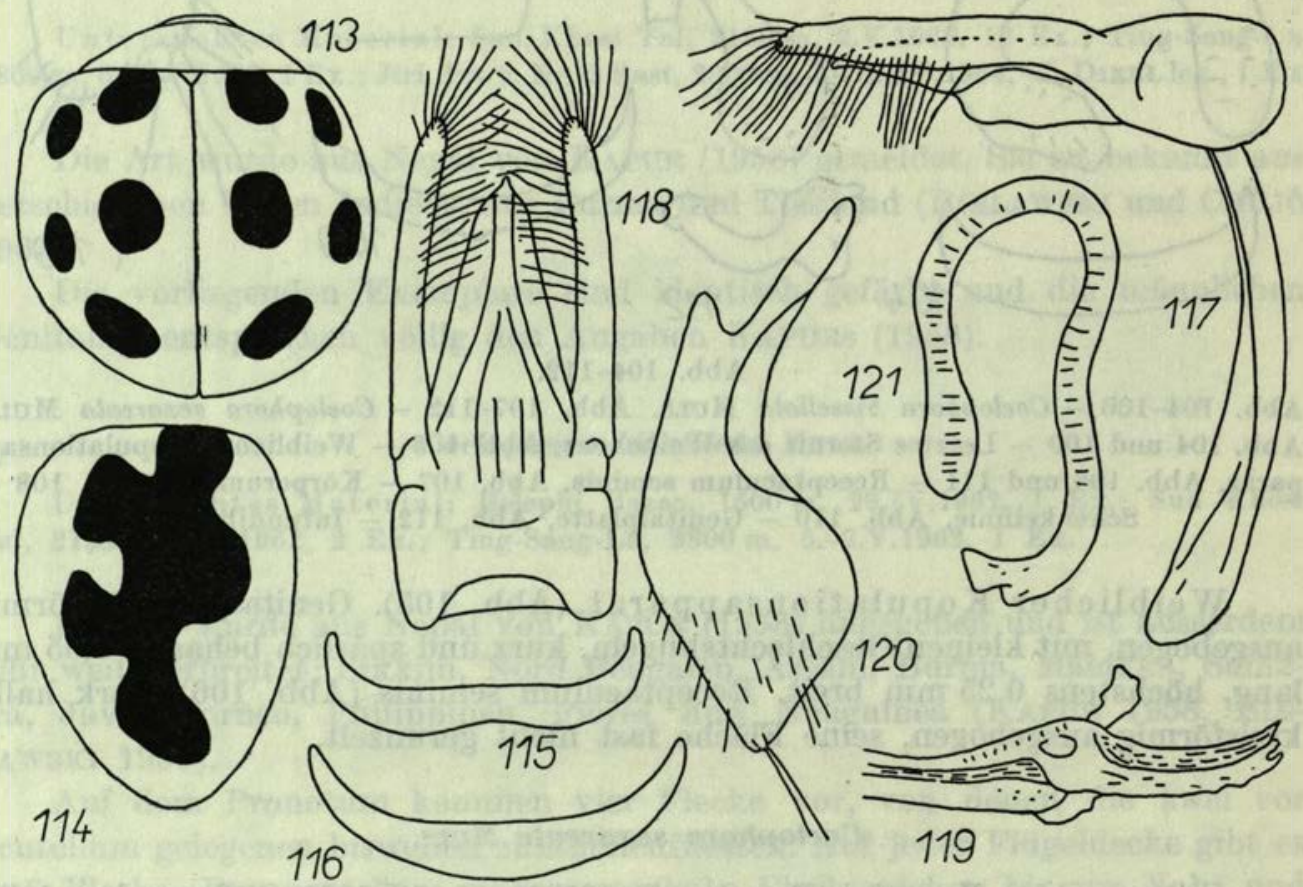

Abb. 113-121. Coelophora eberti sp. n.

Abb. 113 - Körperumriss, Abb. 114 - Flügeldecke, Abb. 115 - Letztes Sternit des Männchens, Abb. 116 - Letztes Sternit des Weibchens, Abb. 117 und 118 - Kopulationsapparat des Männchens, Abb. 119 - Ende des Siphos von der Seite, Abb. 120 - Genitalplatte, Abb. 121 - Receptaculum seminis. 
merklich, doch deutlich eingeschnittenen Seitenrändern. Punkte auf dem Pronotum recht gross, so dicht angeordnet, dass die Abstände zwischen ihnen kleiner als die Durchmesser der Punkte erweisen. Zwischenräume glänzend. Scutellum rotbräunlich, seike Basis ein wenig länger als die übrigen Ränder. Flügeldecken rotbraun mit je fünf recht grossen schwarzen Flecken (Abb. 113). 1. Fleck näher der Naht als dem Seitenrande gelegen und die Basis der Decke erreichend. 2. Fleck liegt unterhalb der Schulterbeule, fast gleich von der Basis und vom Seitenrande entfernt. 3. Fleck befindet sich in halber Länge der Flügeldecke, näher der Naht. 4. Fleck in Verhältnis zum 3. etwas nach hinten verschoben, und sein Abstand von dem Seitenrand gleich jenem des 2. Fleckes. 5. Fleck in der hinteren Hälfte der Flügeldecke, etwas näher der Naht als dem Seitenrand gelegen. Alle Flecke können miteinanderfliessen und bilden dann ein unregelmässiges Dessin in Form eines grossen Fleckes (Abb. 114), wobei es deutlich ersichtlich ist, dass dieser grosse Fleck von den fünf normalen Flecken durch Zusammenfliessen entstand. Seitenränder der Flügeldecken kaum abstehend, an den Schultern etwas das Pronotum deckend. Schulterbeulen kaum angedeutet. Punkte auf den Flügeldecken gross, grösser als jene auf dem Pronotum, tief und so dicht angeordnet, dass die Abstände kleiner als die Durchmesser der Punkte erscheinen. Am Seitenrand der Flügeldecken Punkte noch grösser. Die Räume zwischen den Punkten glatt und glänzend. Beine und Bauchfläche des Körpers rotbraun. Krallen einfach, mit grossem Lappen an der Basis. Schenkellinie unvollständig, erreicht mit ihrer Ausbiegung fast den Hinterrand und verläuft weiterhin parallel zu ihm, reicht jedoch bis zum Seitenrand nicht. Letztes Sternit des Männchens (Abb. 115) sehr kurz, mit stark bogenförmig eingeschnittenem Hinterrand, kurz behaart. Letztes Tergit mit sehr langen Basalfortsätzen. Letztes Sternit des Weibchens (Abb. 116) kurz, an den Seiten stark ausgebogen und verlängert, mit zugespitzten Enden, kurz und spärlich behaart. Letztes Tergit nicht allzu lang, mit kurzen Basalfortsätzen.

Körper 4,0-4,8 mm lang, 3,8-4,6 $\mathrm{mm}$ breit.

Männlicher Kopulationsapparat (Abb. 117-118). Penis kürzer als die Parameren, von der Seite betrachtet fast gerade, bloss am Ende unmerklich gekrümmt, von unten betrachtet von der Basis an allmählich enger werdend und am Ende in eine kurze, schmale, stumpfe Spitze verlängert. Länge des Penis $0,54 \mathrm{~mm}$, grösste Breite (von unten gesehen) $0,27 \mathrm{~mm}$. Parameren gerade, lang und reichlich behaart. Basalteil fast kreisrund. Trabes lang, von der Basis an sich allmählich erweiternd, kaum länger als die Parameren samt Basalteil. Sipho recht massiv, stark ausgebogen, mit grosser Kapsel, seine Endung wie an der Abb. 119.

Weiblicher Kopulationsapparat. Genitalplatten (Abb. 120) schräg gestellt, unmerklich S-förmig gebogen, vor der Basis eingeschnitten. Geschlechtshügel klein, spärlich behaart. Länge der Genitalplatte $0,65 \mathrm{~mm}$, grösste Breite 
$0,25 \mathrm{~mm}$. Receptaculum seminis (Abb. 121) sehr lang, stark ausgebogen, schmal, am Ende kaum erweitert.

Holotypus: „Nepal, Indrawati Khola, Saretar, 1700 m, 25.-26.IV.1962, G. EBERT leg." - Männchen. Paratypen: 1 Weibchen von gleicher Lokalität wie der Holotypus und 1 Weibehen von: „Ting-Sang-La, $3800 \mathrm{~m}$, 6.-7.V.1962, G. EBERT leg.”. Der Holotypus und 1 Paratypus werden in der Zoologisehen Sammlung des Bayerisehen Staates in Münehen und 1 Paratypus im Zoologisehen Institut der PAdW in Warszawa aufbewahrt.

Die neue Art unterscheidet sich deutlich von den anderen Arten der Gattung durch das Dessin der Flügeldecken und besonders durch die Lage des 1 . Fleckes, der die Basis der Flügeldecke erreicht. Durch die Anzahl und Anordnung der Flecke ähnelt $C$. eberti am meisten der von Indien, Java, China und Hawai bekannten (KAPUR 1963b) C. pupillata (Sw.), unterscheidet sich jedoch von dieser Art durch die Körpergrösse und Punktierung der Flügeldecken - die Punkte bei $C$. pupillata sind zweierlei (gross und klein) und die Zwischenräume mit schwachem, doch deutlichem Mikrorelief, während $C$. eberti nur nicht differenzierte, grössere Punkte und glatte Zwischenräume hat.

\section{Menochilus sexmaculatus (F.)}

Untersuchtes Material: Jiri, Prov. Nr. 2 East, 2000 m, 1.-12.IV.1964, W. DIERL leg., 1 Ex.

Eine weit verbreitete Art: Neuguinea, Molukken, Philippinen, Celebes, Borneo, Java, Sumatra, Andamanen, Yunnan, Nordindien (Assam, Nord-Bengalen), Sikkim, Nepal, Westpakistan. Am meisten westlich von Iran gemeldet (BIFLAWSKI 1956). Für Nepal von KAPUR (1958) nachgewiesen.

Das vorliegende Exemplar hat auf jeder Flügeldecke zwei Querbinden und einen Fleck, die jedoch weder den Seitenrand noch die schwarze Naht erreichen.

\section{Verania inops (MULs.) f. vineta GoRH.}

Untersuchtes Material: Rapti Tal, 300 m, Megouli, 1.IV.1962, G. EBert leg., 4 Ex.

Die Form ist bisher nur von Burma und Thailand bekannt (BIELAWSKI und CHÔJô 1964) und neu für die Fauna Nepals.

Von der typischen Form unterscheidet sie sich dadurch, dass jeder Flügeldecke entlang ein schmales, schwarzes Längsband verläuft, das an der Schulterbeule beginnt und unweit dem Hinterrande endet.

\section{Adomia variegata doubledayi MuLs.}

Untersuchtes Material: Jiri, $1900 \mathrm{~m}, 17 .-19 . V .1962$, G. EBERT leg., 2 Ex.; Thodung, Prov. Nr. 2 East, 3200 m, 14.-21.IV.1964, W. DierL leg., 17 Ex. 
Die Unterart wurde aus Nepal schon von KAPUR (1958) gemeldet und ist ausserdem aus Indien und Kaschmir bekånnt (KORSCHEFSKY 1932).

Die vorliegenden Exemplare aus Nepal haben auf den Flügeldecken je 13 Flecke, die bei allen untersuchten Stücken vergrössert und auf verschiedene Weise miteinander verbunden sind (Abb. 122-130).
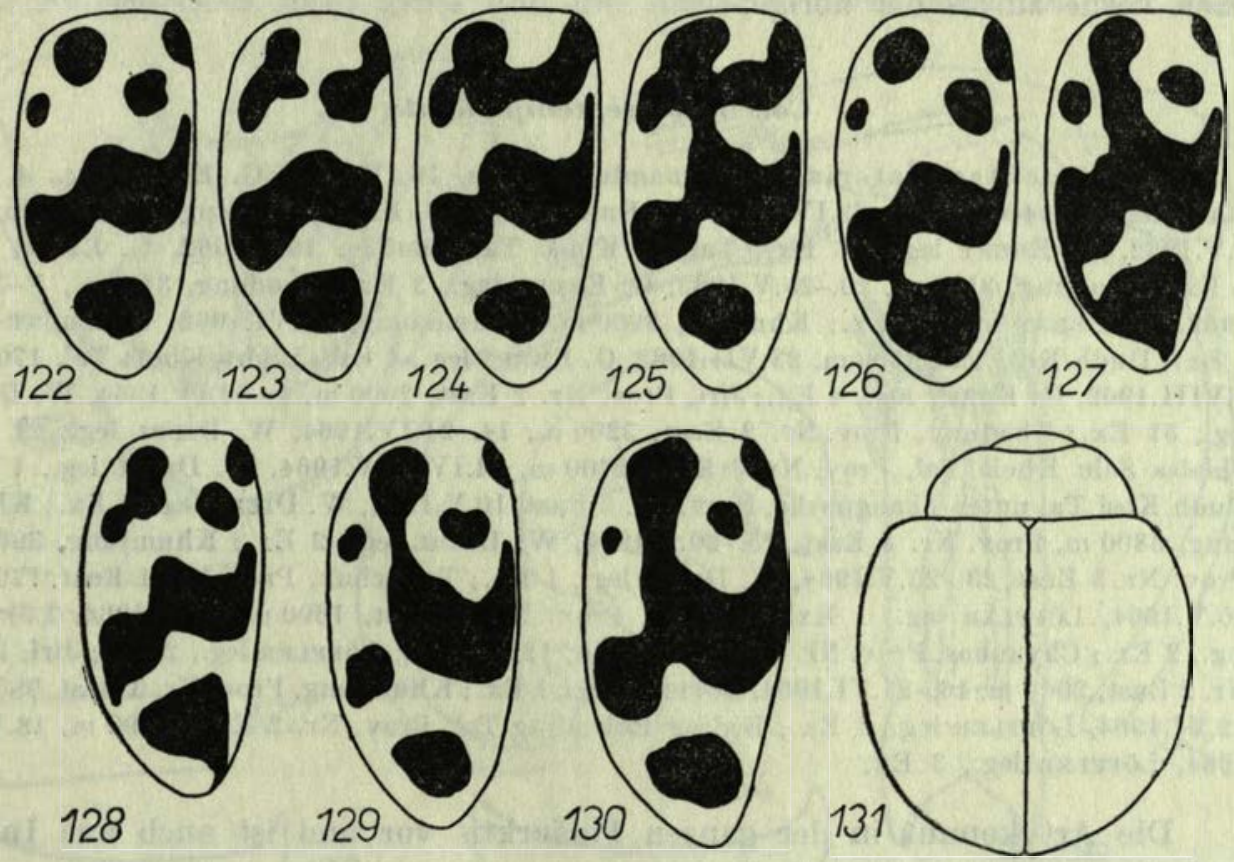

Abb. 122-131.

Abb. 122-130 - Adonia variegata doubledayi Muls., Flügeldecken, Abb. 131 - Calvia albida sp. n., Körperumriss.

\section{Lioadalia luteopicta (MuLs.)}

Untersuchtes Material: Khumbu, Khumdzung, $3900 \mathrm{~m}, 12 .-16$. VI.1962, G. EBERT leg., 4 Ex.; Dudh Kosi Tal, 3500 m, 23.VII.1962, G. EвERт leg., 3 Ex.; Khumbu Periche, 4350 m, 29.VI.1963, G. Ebert leg., 1 Ex.; Khumjung, Prov. Nr. 3 East, 3800 m, 15.-20.V. 1964, W. Drent leg., 1 Ex.; Beding, Rolwaling, Prov. Nr. 2 East, 3940 m, 18.VIII.1964, LÖFFLER leg., 1 Ex.

Aus Nepal schon von KAPUR (1958) gemeldet, sonst aus Nordost-Indien, Sikkim, Tibet und China bekannt.

Alle vorliegenden Stücke identisch gefärbt.

\section{Adalia tetraspilota (HOPE)}

Untersuchtes Material: Jiri, $2000 \mathrm{~m}$, VIII.1961, Gruber leg., 1 Ex.

Für Nepal von KAPUR (1958) nachgewiesen, bekannt aus West-Turkestan, Afghanistan, Indien und Sikkim. 
Das vorliegende Exemplar hat zwei kleine weisse Fleckchen auf dem Kopf. Pronotum kremfarbig mit einem grossen, an der halben Länge der Seitenränder unmerklich erweiterten, den Vorderrand nicht erreichenden Fleck. Scutellum schwarz. In der halben Länge der Flügeldecken treten je zwei schwarze Flecke auf. Der näher der Naht gelegene Fleck ist kleiner und liegt mehr nach vorne zu als der übrige.

\section{Coccinella septempunctata L.}

Untersuchtes Material: Kathmandu, 1400 m, 16.IV.1962, G. EBERT leg., 4 Ex.; Kathmandu, 1400 m, 21.-23.IV.1962, G. EBERT leg., 21 Ex.; Ting-Sang-La, 3800 m, 6.7.V.1962, G. Ebert leg., 26 Ex.; Tampa Khosi Tal, 2600 m, 10.V.1962, G. Ebert leg., 4 Ex.; Thodung, $3100 \mathrm{~m}$, 20.-25.V.1962, G. EBert leg., 3 Ex.; Thodung, $3100 \mathrm{~m}, 1$.-3.VI. 1962, G. EвERT leg., 4 Ex.; Khumbu, 3900 m, Khumdzung, 20.VI.1962, G. Ebert leg., 2 Ex.; Dudh Kosi Tal, 3500 m, 23.VII.1962, G. EBert leg., 1 Ex.; Likhu Khola Tal, 1700 m, 1.VIII.1962, G. Ebert leg., 4 Ex.; Jiri, Prov. Nr. 2 East, 2000 m, 1.-12.IV.1964, W. DierL leg., 51 Ex.; Thodung, Prov. Nr. 2 East, 3200 m, 14.-21.IV.1964, W. DienL leg., 21 Ex.; Chialsa Solu Khola Tal, Prov. Nr. 3 East, 2700 m, 24.IV.-1.V.1964, W. DrenL leg., 1 Ex.; Dudh Kosi Tal unter Thangpoche, Prov. Nr. 3 East, 10.V.1964, W. DierL leg., 1 Ex.; Khumjung, $3800 \mathrm{~m}$, Prov. Nr. 3 East, 15.-20.V.1964, W. DienL leg., 2 Ex.; Khumjung, $3800 \mathrm{~m}$, Prov. Nr. 3 East, 23.-25.V.1964, W. Dierl leg., 1 Ex.; Tultschuk, Prov. Nr. 1 East, 1700 m. 30.V.1964, Löfrler leg., 1 Ex.; Banepa, Prov. Nr. 1 East, 1600 m, 9.VI.1964, Löffler leg., 2 Ex.; Chyaubas, Prov. Nr. 1 East, 2400 m, 12.VI.1964, Löfrler leg., 2 Ex.; Jiri, Prov. Nr. 2 East, 2000 m, 16.-21.VI.1964, LÖFfLER leg., 1 Ex.; Khumjung, Prov. Nr. 3 East, 3800 m, 22.VI.1964, Löffler leg., 1 Ex.; Beding Rolwaling Tal, Prov. Nr. 2 East, 3990 m, 18.VIII 1964, LÖFFLER leg., 3 Ex.

Die Art kommt in der ganzen Paläarktis vor und ist auch aus Indien und Nepal (KAPUR 1958) bekannt.

Unter den 156 vorliegenden Exemplaren sind die Flecke auf den Flügeldecken bei 45 Exemplaren stark vergrössert und zusammengeflossen.

\section{Calvia albida sp. n.}

Körper schwach gewölbt, in Gestalt eines breiten Ovals (Abb. 131). Obere und untere Körperfläche einheitlich gelblich, Mundanhänge, Fühler, Beine und sehr schmal auch die Naht gelbbräunlich. Punkte auf dem Kopf sehr klein und äusserst selten angeordnet, so dass die Abstände zwischen ihnen mehrfach grösser als die Durchmesser der Punkte sind. Punktierung wegen stark entwickeltes, gitterförmiges Mikroreliefs kaum sichtbar. Mandibeln mit zwei apikalen und einem basalen Zahn. Der innere Apikalzahn ohne zusätzliche Zähnchen. Fühler lang und schlank, über die halbe Länge des Pronotums reichend. 3. Fühlerglied länger als 2. oder 4. Letztes Keulenglied am Ende unmerklich abgeschnitten. Vorderrand des Pronotums gerade, Seitenränder schwach bogenförmig, Vorderwinkel abgerundet und kaum nach vorne hervorragend. Die Oberfläche des Pronotums nahe den Hinterwinkeln unmerklich konkav. Punkte 
auf dem Pronotum klein, seicht, so selten angeordnet, dass die Abstände 23mal grösser als die Durchmesser der Punkte erscheinen. Zwischenräume mit recht deutlichem Mikrorelief in Form eines zerrissenen Gitters. Scutellum gleichseitig, mit deutlichem Mikrorelief. Flügeldecken seitlich breit aber schwach abgebogen. Schulterbeulen recht gross, jedoch kaum vorspringend. Punkte auf den Flügeldecken recht gross und die Abstände zwischen ihnen nur kaum

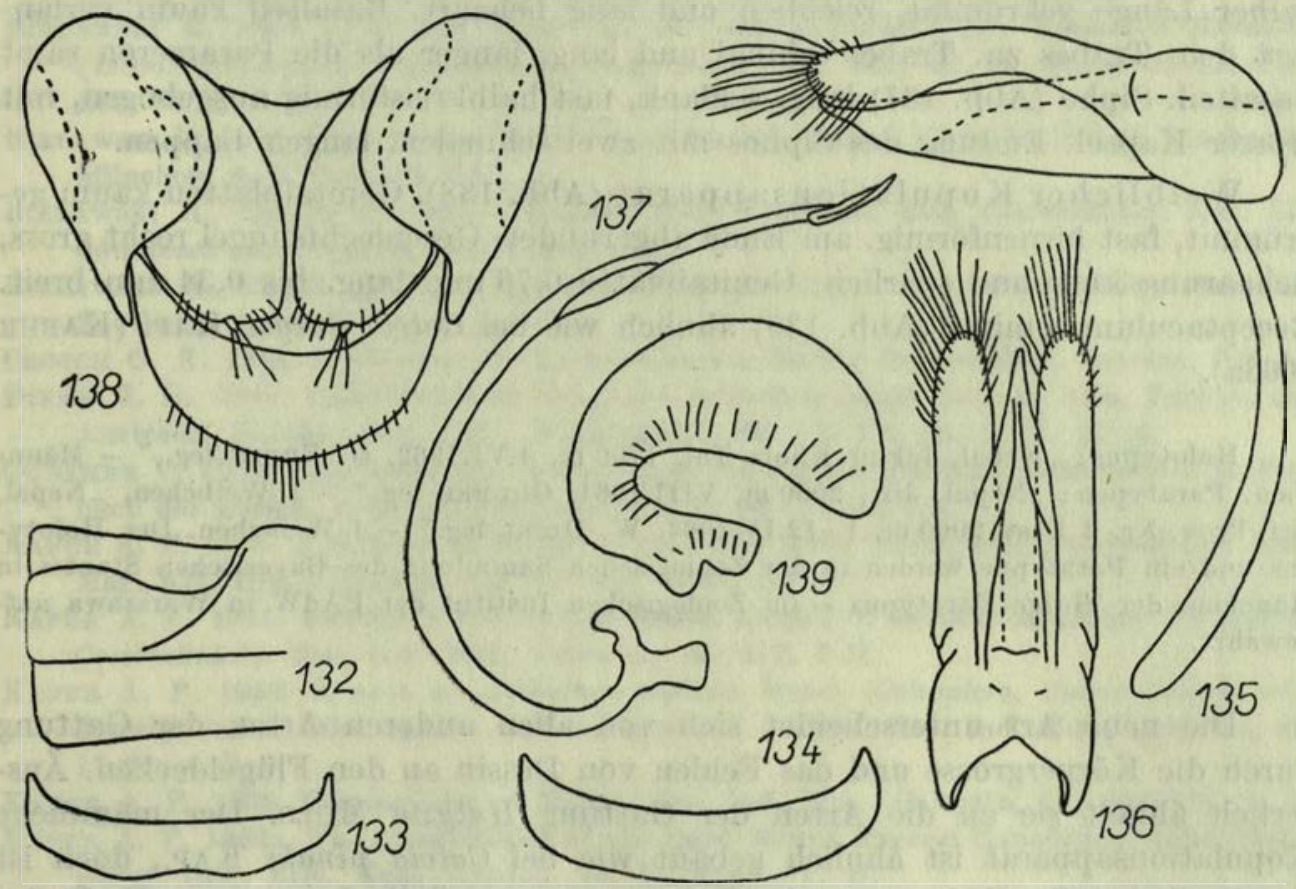

Abb. 132-139. Calvia albida sp. n.

Abb. 132 - Schenkellinie, Abb. 133 - Letztes Sternit des Männchens, Abb. 134 - Letztes Sternit des Weibchens, Abb. 135 und 136 - Kopulationsapparat des Männehens, Abb. 137 - Sipho, Abb. 138 - Weiblicher Kopulationsapparat, Abb. 139 - Receptaculum seminis.

grösser als ihre Durchmesser. Die Grösse der Punkte kaum schwankend. Zwischenräume mit undeutlichem Mikrorelief in Form von Anstichen und unregelmässigen Stricheln. Kralle einzeln, mit einem deutlichen, breiten Lappen an der Basis. Vorderrand des Mesosternums in seiner halben Länge deutlich eingeschnitten. Rippchen des Prosternums fast unsichtbar. Schenkellinie (Abb. 132) unvollständig, mit ihrer Ausbiegung fast den Hinterrand erreichend und dort endend. Letztes Sternit des Männchens (Abb. 133) kurz, mit schwach bogenförmig eingeschnittenem Hinterrand. Letztes Tergit des Männchens mit sehr kurzen Basalfortsätzen und kaum eingebogenem Hinterrand. Letztes Sternit des Weibchens (Abb. 134) kurz, mit regelmässig ausgebogenem Hinterrand. Letztes Tergit des Weibchens mit langen und breiten Basalfortsätzen. 
Körper $8 \mathrm{~mm}$ lang, $6,4 \mathrm{~mm}$ breit.

Männlicher Kopulationsapparat (Abb. 135-136). Penis kaum kürzer als die Parameren, von der Seite betrachtet fast gerade und von der Basis an allmählich enger werdend, von unten betrachtet am breitesten in seiner halben Länge und von dort an jäh aber allmählich enger werdend. Länge des Penis $0,9 \mathrm{~mm}$, grösste Breite (von der Seite) $0,3 \mathrm{~mm}$. Parameren recht breit, in halber Länge gekrümmt, reichlich und lang behaart. Basalteil kaum verlängert dem Trabes zu. Trabes schmal und lang, länger als die Parameren samt Basalteil. Sipho (Abb. 137) lang, schlank, fast halbkreisförmig ausgebogen, mit grosser Kapsel. Endung des Siphos mit zwei schmalen, langen Lappen.

Weiblicher Kopulationsapparat (Abb. 138). Genitalplatten kaum gekrümmt, fast birnenförmig, am Ende abgerundet. Geschlechtshügel recht gross, Behaarung kurz und spärlich. Genitalplatte $0,76 \mathrm{~mm}$ lang, bis $0,34 \mathrm{~mm}$ breit. Receptaculum seminis (Abb. 139) ähnlich wie bei Calvia durgae KAP. (KAPUR 1963a).

Holotypus: „Nepal, Likhu Khola Tal, 1700 m, 4.VI.1962, G. EвERT leg.,” - Männchen. Paratypen: „Nepal, Jiri, 2000 m, VIII.1961, GRUBER leg.” - 1 Weibchen, „Nepal, Jiri, Prov. Nr. 2 East, 2000 m, 1.-12.IV.1964, W. DienL leg." - 1 Weibchen. Der Holotypus und ein Paratypus werden in der Zoologischen Sammlung des Bayerischen Staates in München, der übrige Paratypus - im Zoologischen Institut der PAdW in Warszawa aufbewahrt.

Die neue Art unterscheidet sich von allen anderen Arten der Gattung durch die Körpergrösse und das Fehlen von Dessin an den Flügeldecken. Äusserlich ähnelt sie an die Arten der Gattung Halyzia MuLs. Der männliche Kopulationsapparat ist ähnlich gebaut wie bei Calvia pinaki KAP., doch ist der Penis bei $C$. albida sp. n. deutlich massiver und die Lappen am Ende des Siphos mehr schlank und länger. Die Genitalplatten bei $C$. albida sp. n. haben ähnliche Gestalt wie bei $C$. durgae KAP.

Instytut Zoologiczny PAN

Warszawa, Wilcza 64

\section{LITERATUR}

Bı⿻LAwski R. 1956. Coccinelliden aus Iran 1954 (Coleopt.). Jh. Ver. vaterl. Naturk. Württemberg, Stuttgart, 111: 76-81, 6 ff.

BIELAwski R. 1959. Coccinellidae (Coleopt.) von Sumba, Sumbawa, Flores und Bali. Verh. naturf. Ges., Basel, 69: 145-166, 83 ff. 
Bielawski R. 1960. Materialien zur Kenntnis der Ooccinellidae (Ooleoptera). Ann. zool., Warszawa, 18: 435-458, 43 ff.

Brelawski R. 1961. Materialien zur Kenntnis der Coccinellidae (Coleoptera) II. Ann. zool., Warszawa, 19: 383-415, $74 \mathrm{ff}$.

Bielawski R. 1962. Materialieñ zur Kenntnis der Cocoinellidae (Coleoptera) III. Ann. zool., Warszawa, 20: 193-205, 37 ff.

BIELAWSKI R. 1963. Monographie der Epilachninae (Coleoptera, Coccinellidae) der Australischen Region. Ann. zool., Warszawa, 21: 295-461, 403 ff., 2 Karten.

BIELAWSKI R. 1964. Uber drei Arten aus der Verwandtschaft von Epilachna flavicollis (ThBg.) (Coleoptera, Coccinellidae). Bull. Acad. pol. Sci., Cl. II, Varsovie, 12: 255$262,34 \mathrm{ff}$.

BIELAWsKI R. 1971. Uber Ooccinellidae (Ooleoptera) aus Nepal. Khumbu Himal, InnsbruckMünchen, 4, 1: 1-9, $35 \mathrm{ff}$.

Bielawski R., Chôjô M. 1961. Ooleoptera from Southeast Asia, Coccinellidae. Nat. Life Southeast Asia, Kyoto, 1: 331-334, 9 ff.

Bielawski R., Chôjô M. 1964. Coleoptera from Southeast Asia, Coccinellidae. Nat. Life Southeast Asia, Kyoto, 3: 226-228.

Свотсн G. R. 1874. A revision of the coleopterous family Coccinellidae. London, $311 \mathrm{pp}$.

Dieke G. H. 1947. Ladybeetles of the genus Epilachna (sensu lato) in Asia, Europe, and Australia. Smiths. misc. Coll., Washington, 106, 15, 183 pp., 6 ff., 27 tt.

GüNTher V. 1958. Ergebnisse der Zoologischen Expedition des Nationalmuseums in Prag nach der Türkei. Acta ent. Mus. nat., Praha, 32: 19-36, 8 ff.

KAPUR A. P. 1946. A revision of the genus Jauravia Mots. (Ooleoptera, Ooccinellidae). Ann. Mag. nat. Hist., London, Ser. 11, 13: 73-93, $30 \mathrm{ff}$.

KAPUR A. P. 1951. Further notes on the Indian species of Rodolia Mulsant (Coleoptera, (occinellidae). Rec. Ind. Mus., Calcutta, 48: 1-7, 2 ff.

KAPUR A. P. 1952. A note on Epilachna ocellata REDT. (Coleoptera, Coccinellidae), with descriptions of three species hitherto confused with it. Rec. Ind. Mus., Calcutta, 48 : 17-29, 4 ff.

KAPUR A. P. 1958. Ooccinellidae of Nepal. Rec. Ind. Mus., Calcutta, 53: 309-338, 12 ff.

KaPUR A. P. 1963a. The Coccinellidae of the third Mount Everest Expedition, 1924 (Coleoptera). Bull. Brit. Mus., London, 14, 1, 48 pp., $17 \mathrm{ff}$.

KAPUR A. P. 1963b. Confirmation of the occurrence of the lady-beetle Coelophora pupillata (Swartz) (Coccinellidae, Coleoptera), in India and its biological importance. Sc. Culture, Calcutta, 29: 264.

Korschefsky R. 1931. Cocoinellidae I. In: Junk W. „Coleopterorum Catalogus”, Pars 118, Berlin, 224 pp.

KoRschefsky R. 1932. Coccinellidae II. In: JUNK W. „Coleopterorum Catalogus”, Pars 120, Berlin, pp. 225-659.

Mader L. 1930. Neue Coccinelliden aus Yün-nan und Szetschwan (China). Ent. Anz., Wien, 10: 161-184, $11 \mathrm{ff}$.

Mulsant E. 1850. Species des coléoptères trimères sécuripalpes. Ann. Soc. agr., Lyon, (2), 2, $1104 \mathrm{pp}$.

Mulsant E. 1853. Supplément à la monographie des coléoptères trimères sécuripalpes. Ann. Soc. Linn., Lyon, N. S., 1: 129-333.

SiCARD A. 1912. Coccinellides nouveaux de la collection de M. WALTER DE Rägern (Moravie). Ann. Soc. ent. France, Paris, 81: 507-513.

WeIse J. 1898. Uber bekannte und neue Coccinelliden. Arch. Naturg., Berlin, 64: 225-238.

WeISE J. 1908. Coleoptera aus Ostindien. Ent. Zeit., Stettin, 69: 213-230. 
[Tytuł: Biedronki (Coleoptera: Coccinellidae) z Nepalu]

Autor omawia 40 gatunków, spośród których 3 gatunki są nowe dla nauki, a mianowicie Cryptogonus nepalensis sp. n., Coelophora eberti sp. n. i Calvia albida sp. n. 15 gatunków nie było dotychezas wykazywanych z Nepalu. Obecnie znane są z Nepalu 62 gatunki biedronek. Wśród nich duży procent stanowią endemity, następnie elementy indo-malajskie i w końcu nieliczne gatunki palearktyczne.

РЕЗЮMЕ

[Заглавие: Coccinellidae (Coleoptera) из Непала]

Автор рассматривает 40 видов Coccinellidae, из которых 3 вида описываются впервые. Это: Cryptogonus nepalensis sp. n., Coelophora eberti sp. $\mathrm{n}$. и Calvia albida sp. n. 15 видов не были до сего времени констатированы для Непала. В настоящее время известно из Непала 62 вида. Значительный процент среди них составляют эндемические виды, затем элементы индо-малайской фауны и лишь незначительное число палеарктические виды.

Redaktor pracy - doc. dr A. Riedel 
http://rcin.org.pl 


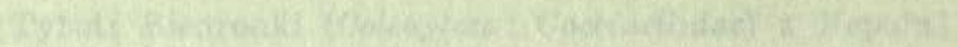

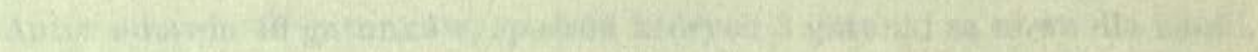

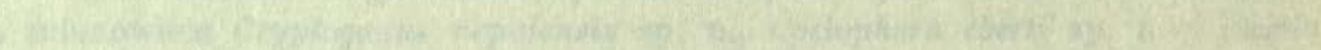

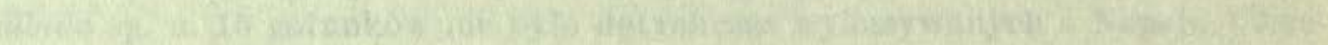

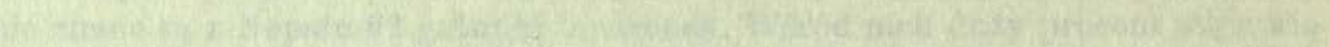

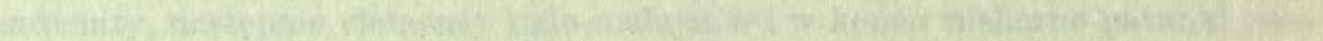

tan

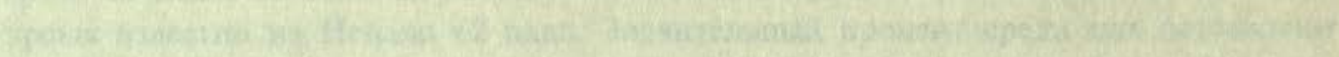

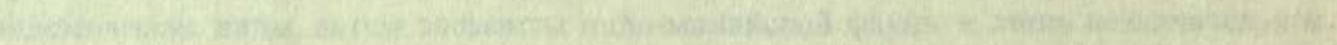

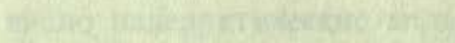

http://rcin.org.pl 